\title{
RETAILER'S JOINT PRICING MODEL THROUGH AN EFFECTIVE PRESERVATION STRATEGY UNDER A TRADE-CREDIT POLICY
}

\author{
Abu Hashan Md Mashud ${ }^{1}$ And Biswajit SARKar ${ }^{2}$
}

\begin{abstract}
Sustainable inventory management is a common issue for any industry. This proposed study explains a representation of mathematical modelling for maintaining sustainability through the preservation technology for deteriorating products and trade-credit strategy for sustainable marketing. Based on the actual life circumstances, it is found that the demand for deteriorated products is influenced by the increasing frequency of advertising and preservation technology. The foremost aim of this study is to maintain sustainability with optimal pricing and optimal strategies to invest in preservation technology and optimal cycle length to take full advantage of the total profit. For solving the model, a classical optimization technique is utilized, and some theoretical results are shown with a graph of the profit function. Couples of experiments compare the proposed results and the existing literature and give some outcomes for different deterioration types. To illustrate and justify the model, a sensitivity analysis conceded for demonstrating the proposed model's flexibility by changing one parameter while keeping others fixed. The result shows that the trade-credit strategy under the preservation technology makes the management's most substantial marketing benefit.
\end{abstract}

Mathematics Subject Classification. 90B05, 90B30.

Received April 25, 2020. Accepted February 6, 2021.

\section{INTRODUCTION}

Inventory is generally known as finished goods or unfinished goods and directly or indirectly relates to all social sectors. Therefore, the appropriate control or management of inventory is an inevitable challenge for the present community. Many factors that are come under proper control or management of stock, deterioration is one of them. The meaning of deterioration is decay or damage, spoilage, evaporation of products $[26,39]$. Several scholars settled their models carrying deterioration as an essential factor to maintain the sustainability of inventory.

In any sustainable inventory model for deteriorated products, decision-making is an essential issue for the management. Even though the management decides the optimum decisions, it may not always be correct based on the physical property of the product [11,18]. Cárdenas-Barrón and Sana [5], Panda et al. [35], and CárdenasBarrón et al. [6] described in their paper that for maintaining the better decision, the management always

Keywords. Advertising, marketing benefit, preservation strategy, sustainability, trade-credit.

1 Department of Mathematics, Hajee Mohammad Danesh Science and Technology University, Dinajpur 5200, Bangladesh.

2 Department of Industrial Engineering, Yonsei University, 50 Yonsei-ro, Sinchon-dong, Seodaemun-gu, Seoul 03722, South Korea.

${ }^{*}$ Corresponding author: bsbiswajitsarkar@gmail.com 
takes several strategies to earn more based on the promotional policies using the variable demand and product deterioration. Therefore, in several studies, some researchers tried to incorporate this vital matter $[2,19,20,41]$, but none developed the combination of preservation of products where the trade-credit policy was adopted under variable demand.

Prior studies on deteriorating items have the basic assumption that the objects' deterioration begins after their immediate appearance in stock. Indeed, the maximum things could have a period of unspoiled importance or unique condition throughout that period, where no deterioration occurs. Ouyang et al. [32] restricted that sensation employing "non-instantaneous deterioration." This type of phenomenon usually occurs in the real world. The deterioration rate is approximately tending to zero for all firsthand vegetables and fruits only for a short duration when it is in new quality. Afterward, specific several of the substances will begin to deteriorate.

As customers always want the best products from the market, traders use various techniques to preserve their products. Preservation minimizes the deterioration rate of products and extends the life of products. Researchers developed several inventory models considering preservation technology (PT) as a crucial feature. Dye and Hseigh [10] designed a model for inventories with effective deals provided in PT; similarly, Dye [9] extended this by adding another feature, non-instantaneous deterioration. Yang et al. [49] combined the preservation technology strategy with the optimal dynamic trade-credit model. Ullah et al. [47] proposed a production model showing the effective use of waste management preservation. Mashud et al. [26] showed how preservation helps the retailer preserve deteriorating products for a long time, while Iqbal et al. [15] proposed a production inventory model for lifetime-dependent products.

In the competitive market, the selling price plays an essential role in marketing strategies. Most customers took their decisions after the confirmation about the cost of the product. It is usually seen that when prices are high, demand falls, and thus it directly affects the customer demand. Many researchers worked on this critical factor, like Zhang et al. [50], presented a deteriorating inventory model considering this price-sensitive demand. Shaikh et al. [40] proposed a study with consideration of price and stock-dependent demand. Taleizadeh et al. [42] presented an exploration that manages the best-selling price, return policy, and quality level for corresponding items on a web-based purchase with a concerted assurance. Mashud et al. [27] incorporated advertisement policy in demand function and developed an inventory model for non-instantaneous deteriorating products. Dey et al. [8] projected an EOQ model for price-sensitive demand under setup cost reduction policy.

Aside from the price, the further marketing factor, which shakes the demand, is advertising. We often see that a company promotes its product through advertisements via TV, radio, newspaper, social media, and any other acceptable media. To attract more customers is the main objective of the advertisement. Sarkar [38] built up an inventory model using the frequency of advertising reliant demand under the reliability of faulty items. Shah et al. [37] additionally built up a model concerned with non-instantaneous deteriorating things where demand depends on advertising and sales pricing activities. Hasan et al. [14] developed an economic order quantity model considering the frequency of advertisement, selling price, and continuous time-dependent demand under the shortages. Earlier, Luo [24] proposed an inventory model by joining the influence of advertisements' frequency with price variations on to the demand, while Yadav et al. [48] developed a supply chain model for price marketing expenditure for the low quality of items.

The current business situation is competitive. Considering this high competition, a supplier provides various facilities to his retailers to promote their business. Among them, trade-credit financing is a popular feature. In trade-credit financing, suppliers offer some credit facility (payment time after receiving the product) to their retailers under specific terms and conditions without prompt installment. Goyal [12] was one of the leading analysts in building an EOQ model, including allowable delay in payments. More remarkably, the trade-credit tactic, which Goyal [12] conferred previously, accepts that the provider deals only with trade-credit; however, the retailer does not grant his/her client any credit. Aggarwal et al. [1] developed Goyal's [12] model by introducing an order policy under approved delay-in-payments for degraded products. Tsao et al. [46] worked on a declining inventory model and incorporated the contemplation of demand reliant on price and time, including the payment system under approval delay. Teng et al. [43] developed a model for increasing demand with a trade-credit strategy. Again, Teng [44] improved that inventory model for increasing demand with a similar trade-credit 
TABLE 1. Overview of corresponding works for deterioration, trade-credit, preservation technology, and shortage.

\begin{tabular}{|c|c|c|c|c|c|c|c|c|}
\hline \multirow[t]{2}{*}{ Author's } & \multicolumn{4}{|c|}{ Demand pattern } & \multirow{2}{*}{$\begin{array}{l}\text { Non- } \\
\text { instantaneous }\end{array}$} & \multirow[t]{2}{*}{ Shortages } & \multirow{2}{*}{$\begin{array}{l}\text { Preservation } \\
\text { technology }\end{array}$} & \multirow{2}{*}{$\begin{array}{l}\text { Trade- } \\
\text { credit }\end{array}$} \\
\hline & $\begin{array}{l}\text { Time- } \\
\text { dependent }\end{array}$ & Price & Stock & Advertisement & & & & \\
\hline $\begin{array}{l}\text { Dye and } \\
\text { Hsieh [10] }\end{array}$ & $\checkmark$ & & & & & $\checkmark$ & $\checkmark$ & \\
\hline $\begin{array}{l}\text { Palanivel } \\
\text { et al. [33] }\end{array}$ & & $\checkmark$ & & $\checkmark$ & $\checkmark$ & $\checkmark$ & & \\
\hline Dye [9] & & & & & $\checkmark$ & $\checkmark$ & $\checkmark$ & \\
\hline $\begin{array}{l}\text { Shah et al. } \\
{[37]}\end{array}$ & & $\checkmark$ & & $\checkmark$ & $\checkmark$ & $\checkmark$ & & \\
\hline $\begin{array}{l}\text { Zhang et al. } \\
{[50]}\end{array}$ & & $\checkmark$ & & & & $\checkmark$ & $\checkmark$ & \\
\hline Liu et al. [22] & & $\checkmark$ & & & & & $\checkmark$ & \\
\hline $\begin{array}{l}\text { Palanivel } \\
\text { et al. }[34]\end{array}$ & & & $\checkmark$ & & & $\checkmark$ & & $\checkmark$ \\
\hline Lu et al. [23] & & $\checkmark$ & $\checkmark$ & & & & & \\
\hline $\begin{array}{l}\text { Jaggi et al. } \\
\text { [17] }\end{array}$ & & $\checkmark$ & & & $\checkmark$ & & & $\checkmark$ \\
\hline $\begin{array}{l}\text { Mashud et al. } \\
{[25]}\end{array}$ & & $\checkmark$ & $\checkmark$ & & $\checkmark$ & $\checkmark$ & & \\
\hline Li et al. [21] & & $\checkmark$ & & & $\checkmark$ & & $\checkmark$ & \\
\hline This paper & & $\checkmark$ & & $\checkmark$ & $\checkmark$ & $\checkmark$ & $\checkmark$ & $\checkmark$ \\
\hline
\end{tabular}

policy associated with ordering quantity. Jaggi et al. [16] studied an economic ordering policy for defective items with credit financing under allowable shortages, while Mittal et al. [30] proposed a retailer's model for defective items with price and time-sensitive demand. After that, Tiwari et al. [45] industrialized an inventory model with permissible delay-in-payments. Mittal et al. [31] introduced human errors and the trade-credit policy in a two-echelon supply chain model. Recently, Mashud et al. [28] incorporated a trade-credit approach with an advance payment system for a two-warehouse model.

In the existing literature, very few researches studied preservation and trade-credit together. Das et al. [7] developed an inventory model for price-sensitive demand with shortages but did not consider trade-credit policy. Another limitation of that paper was that they solved the resultant problem using soft computing methods and could not provide a closed-form solution. Moreover, preservation technology (PT) has a significant impact on the preservation of products from deterioration. For example, a retailer sells a highly deteriorating product (e.g., ice cream) for a long-time using preservation technology.

On the other hand, it is pricey to maintain this technology. However, both strategies (trade-credit and PT) provide better insights to industry managers in this proposed model. Some related papers are presented in Table 1. Besides these issues, some significant contributions are:

(i) The proposed model's principal target is to treasure the optimum cycle period, optimum selling price, and PT investment approaches, whereas exploiting the total profit per unit time.

(ii) A synergy between preservation investment and trade-credit has been studied in the proposed model.

(iii) It provides some pricing strategies to the retailer and simultaneously studies the effect of price, preservation investment, and trade-credit strategy.

A research methodology is set in Figure 1 to show the whole situation. 


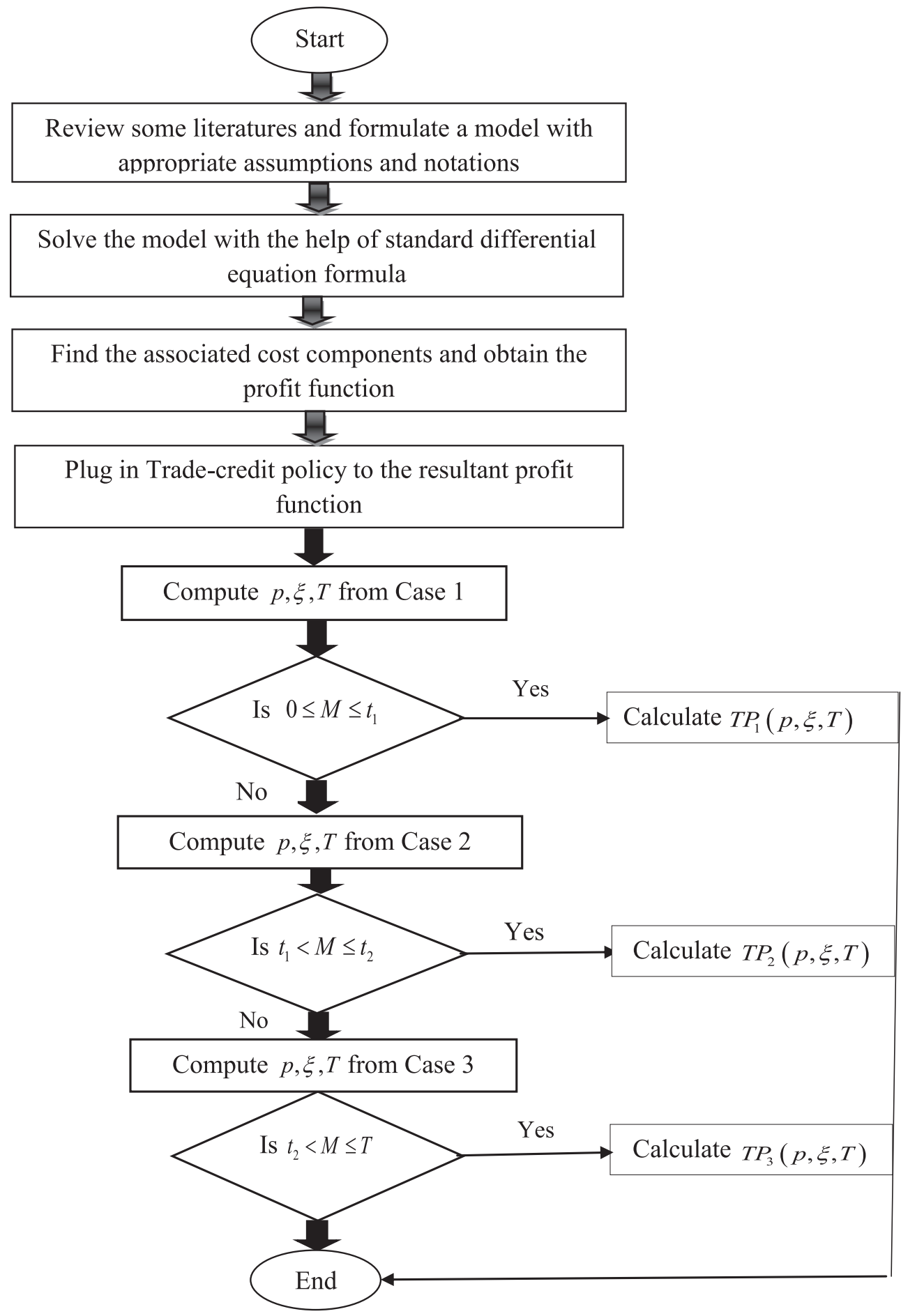

Figure 1. Flowchart of research methodology. 
TABLE 2. Notation for parameters and variables.

\begin{tabular}{|c|c|c|}
\hline Notation & Units & Description \\
\hline & & Decision variables \\
\hline$p$ & $\$ /$ units & Per unit selling price \\
\hline$T$ & time units & Complete cycle length \\
\hline \multirow[t]{2}{*}{$\xi$} & $\$ /$ units & Investment in $\mathrm{PT}$ \\
\hline & & Other variables \\
\hline$t_{1}$ & time units & Time from which the products start to deteriorate \\
\hline$\delta$ & constant & Backlogging parameter \\
\hline$t_{2}$ & time units & Time from which the shortages arise \\
\hline$c$ & $\$ /$ units & Cost to purchase items per order \\
\hline$c_{1}$ & $\$ /$ units & Cost of holding the per unit of purchased items \\
\hline$c_{2}$ & $\$ /$ units & Per unit cost due to shortage \\
\hline$c_{3}$ & $\$ /$ units & Per unit lost sale cost \\
\hline$a_{1}$ & & The preservation investment sensitive parameter \\
\hline$I_{e}$ & Percentage & Retailer's accrued interest rate per unit \\
\hline$I_{c}$ & percentage & Retailer's paid interest rate for delay payments per unit \\
\hline$\gamma$ & $\$ /$ units & Elasticity parameter of advertisement \\
\hline$M$ & time units & The delay period allowed in payment system offered to the retailer \\
\hline$b$ & & Shape parameter \\
\hline$a$ & & The scaling factor related to selling price (e.g., income, fashion) \\
\hline$Q$ & units & Amount of ordered items per cycle \\
\hline$R$ & units & Per cycle utmost amount of shortage \\
\hline$S$ & units & Stock level in the early stages \\
\hline$\Pi(p, \xi, T)$ & $\$ /$ cycle & Per unit aggregate profit \\
\hline
\end{tabular}

\section{Notation AND ASSUMPTIONS}

\subsection{Notation}

The following notation (Tab. 2) and assumptions have been utilized all over the paper.

\subsection{Assumptions}

(i) The inventory model considers reducing deterioration rate by implementing preservation technology for a product (see for reference, [29]).

(ii) In this model, the demand is $D(p)=A^{\gamma}(a-b p)$, which means $D(p)$ be determined by the frequency of advertisement and price for a single deteriorating item. In the full paper for convenience, we alternatively use $D$ or $A^{\gamma}(a-b p), \gamma>0, b>0$ (see for reference, [28]).

(iii) The deterioration rate is considered here $\theta(0<\theta \ll 1)$ as non-instantaneous with an infinite replenishment rate with ignorable lead-time.

(iv) In this proposed model, the similar PT is used as Mishra et al. [29] and He and Huang [13] and which is $m(\xi)=e^{-a_{1} \xi}, \theta$ is the original deterioration rate, $a_{1}$ is the sensitive investment parameter, and it satisfies the conditions $\frac{\partial m(\xi)}{\partial \xi}<0, \frac{\partial^{2} m(\xi)}{\partial \xi^{2}}>0$.

(v) The similar back order rate of Dye [9] is considered in this proposed model, which is $\frac{1}{1+\delta(T-t)}$, where $\delta$ backlogging parameter and $(T-t)$ is waiting time.

\subsection{Problem description}

This model proposes a pricing model from the retailer's perspective. The retailer always tries to increase its profit by incorporating updated marketing strategies such as trade-credit and preservation technology. To 


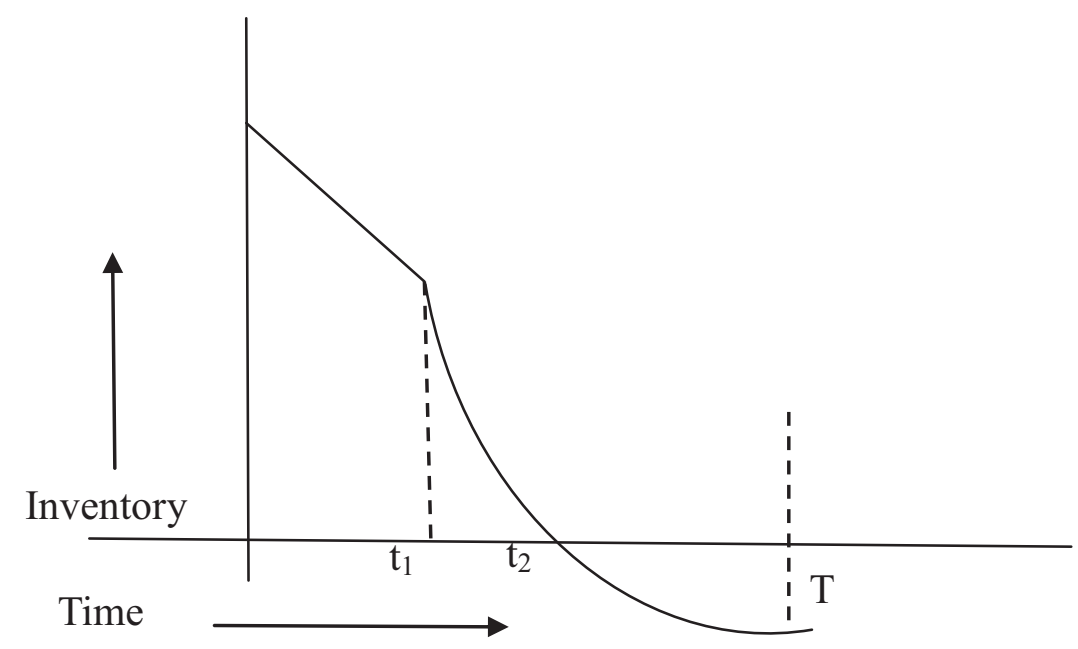

Figure 2. Graphical illustration of inventory level, $I(t)$ with time.

boost sales, the retailer offers a trade-credit policy to its customers. Consequently, due to some uncertainties of demand, the retailer needs to hold the product for an extended period; thus, sometimes, he loses some revenues due to product deterioration and high holding cost. Therefore, the retailer invests in preservation technology to preserve those products without decay for a long time and can sell in good condition. Customer demand always varies based on the selling price. So, considering all these critical three issues simultaneously, a retailer's joint profit model is proposed.

\section{MAThematical MODEL}

Here, $I(t)$ represents the inventory level at any moment $t$, which is portrayed in Figure 2. Due to demand only, the inventory level initiates to decrease in the period $\left[0, t_{1}\right]$ and presents the non-instantaneous period. After that, owing to the consequence of mutual demand with deterioration, $I(t)$ is illustrated in the period $\left[t_{1}, t_{2}\right]$. In this period at $t=t_{2}, I(t)$ falls to zero. Consequently, shortages appeared to occur in the period $\left[t_{2}, T\right]$ and are partially backordered (see for reference Fig. 2). Let, $D=A^{\gamma}(a-b p)$.

Since degradation does not affect the inventory during $\left[0, t_{1}\right]$, so the differential equations can be expressed as below:

$$
I_{1}^{\prime}(t)=-D, \quad 0<t<t_{1}
$$

with $I_{1}(t)=S$ at $t=0$.

By solving equation (3.1) and then applying the above-mentioned condition, we obtain:

$$
I_{1}(t)=S-D t, \quad 0<t \leq t_{1} .
$$

After a time $t=t_{2}$, on account of the joined influence of demand and product deterioration, the stock begins to deplete over time, and toward the finish of this level, it drops to zero. It is expressed mathematically as:

$$
I_{2}^{\prime}(t)+\theta m(\xi) I_{2}(t)=-D, \quad t_{1}<t \leq t_{2}
$$

along with the condition $I_{2}(t)=0$ at $t=t_{2}$. Hence, with the help of these circumstances, the solution of equation (3.3) is set through the resulting equation:

$$
I_{2}(t)=\frac{D}{\theta m(\xi)}\left(e^{\theta m(\xi)\left(t_{2}-t\right)}-1\right), \quad t_{1}<t \leq t_{2} .
$$


Since the inventory levels $I_{1}(t)$ and $I_{2}(t)$ have the same value at $t=t_{1}$, so one can quickly implement the continuity relation at $t=t_{1}$, hence $I_{1}\left(t_{1}\right)=I_{2}\left(t_{1}\right)$ after some manipulation, one can write:

$$
S=D t_{1}+\frac{D}{\theta m(\xi)}\left(e^{\theta m(\xi)\left(t_{2}-t_{1}\right)}-1\right) .
$$

Besides, shortages arise at the time $t=t_{2}$, and consequently, the inventory level begins dropping below zero. During the period of shortages, i.e., in the interval, $\left(t_{2}, T\right)$ the demand at the time $t$ goes to partially backlogged at a fraction $(T-t)$. Hence, the inventory level can be expressed in the following mathematical form at any time $t$ :

$$
I_{3}^{\prime}(t)=\frac{-D}{1+\delta(T-t)}, \quad t_{2}<t \leq T
$$

with $I_{3}(t)=0$ at $t=t_{2}$. By using this boundary condition and some manipulations, one can write the result of the equation (3.6) as

$$
I_{3}(t)=\frac{D}{\delta}\left\{\log (1+\delta(T-t))-\log \left(1+\delta\left(T-t_{2}\right)\right)\right\}, \quad t_{2}<t \leq T .
$$

It is clear from the figure that it has some unsatisfied demand due to lack of stock in the cycle. Therefore, the maximum amount of demand, which is needed to backlog per cycle for satisfying the customers' demand, specified in this form

$$
R=-I_{3}(T)=\frac{D}{\delta}\left\{\log \left(1+\delta\left(T-t_{2}\right)\right)\right\}
$$

Both the initial stock and total amount of shortages are clear from equations (3.5) and (3.8).

Thus, one can easily find the total amount of products ordered per cycle, which is specified as:

$$
Q=S+R=D t_{1}+\frac{D}{\theta m(\xi)}\left(e^{\theta m(\xi)\left(t_{2}-t_{1}\right)}-1\right)+\frac{D}{\delta}\left\{\log \left(1+\delta\left(T-t_{2}\right)\right)\right\} .
$$

Once the order is confirmed, the retailer needs to compensate a certain quantity of cash for buying the goods. Therefore, the mathematical form of the total purchase cost for the whole cycle can be written as:

$$
f_{\mathrm{PC}}=c Q=c\left[D t_{1}+\frac{D}{\theta m(\xi)}\left(e^{\theta m(\xi)\left(t_{2}-t_{1}\right)}-1\right)+\frac{D}{\delta}\left\{\log \left(1+\delta\left(T-t_{2}\right)\right)\right\}\right] .
$$

Holding the stock for the whole cycle is essential to get the maximum profit from the system. As the retailer cannot sell all his available stocks at the beginning of his business, he has to keep stock for a fixed duration to clear the lot. During this period of holding, the retailer must expend some capital on it so that the stock's quality remains unchanged for a certain period. The mathematical form of that cost while holding the products in the complete cycle, can be stated as follows:

$$
\begin{aligned}
f_{\mathrm{HC}} & =c_{1} \int_{0}^{t_{1}} I_{1}(t) \mathrm{d} t+c_{1} \int_{t_{1}}^{t_{2}} I_{2}(t) \mathrm{d} t \\
& =c_{1}\left[S t_{1}-\frac{D t_{1}^{2}}{2}-\frac{D}{\theta^{2} m(\xi)^{2}}\left(1-e^{\theta m(\xi)\left(t_{2}-t_{1}\right)}+\theta m(\xi)\left(t_{2}-t_{1}\right)\right)\right] .
\end{aligned}
$$

However, even after satisfying the demand of several customers, the seller cannot satisfy some customers' demand from the running lot and therefore promises the customers that these will be completed with a later delivery date on the next lot's arrival. Therefore, mathematically the value of cost in the whole cycle is given as follows: 


$$
\begin{aligned}
f_{\mathrm{BC}} & =C_{2} D \frac{1}{\delta}\left[\int_{t_{2}}^{T}\left\{\log \left(1+\delta\left(T-t_{2}\right)\right)-\log (1+\delta(T-t))\right\} \mathrm{d} t\right] \\
& =c_{2}\left[\left(R+\frac{D}{\delta}\left(T-t_{2}\right)\right)-\frac{D}{\delta^{2}}\left(1+\delta\left(T-t_{2}\right)\right) \log \left(1+\delta\left(T-t_{2}\right)\right)\right] .
\end{aligned}
$$

Despite satisfying the demand of the customer, some demands are lost. Those customers are not ready to take late offers from the retailer or hurry to buy products. The revenue that could be achieved by its alternative use of a product or service is called opportunity cost. Because of the impact of lost sales, the opportunity cost in the full cycle is stated as:

$$
\begin{aligned}
f_{\mathrm{LSC}} & =c_{3} \int_{t_{2}}^{T}\left\{1-\frac{1}{1+\delta(T-t)}\right\} D \mathrm{~d} t \\
& =\frac{c_{3} D}{\delta}\left\{\delta\left(T-t_{2}\right)-\log \left(1+\delta\left(T-t_{2}\right)\right)\right\} .
\end{aligned}
$$

By selling products to the customer, the retailer earns some revenue, known as sales revenue. So, the total sales revenue for the complete cycle can be written as:

$$
f_{\mathrm{SR}}=p\left[D t_{2}+\frac{D}{\delta}\left\{\log \left(1+\delta\left(T-t_{2}\right)\right)\right\}\right] .
$$

A retailer always wants to preserve products for a long time to use the best of them. However, to preserve products always needs some extra nourishment and which also costing some expenses. Now those expenses can be expressed in the mathematical form as PT cost in the complete cycle:

$$
f_{\mathrm{PTC}}=\xi T \text {. }
$$

Now suppose the supplier provides the retailer a permissible delay period $M$ within which time the retailer must pay the full amount. Based on that period, there may arise some conditions on the whole cycle length, which can be inscribed as:

Case 1. $0<M \leq t_{1}$.

Case 2. $t_{1}<M \leq t_{2}$

Case 3. $t_{2}<M \leq T$.

Now in detail discussing those above-stated cases:

Case 1. When $0<M \leq t_{1}$.

Here the length of the approvable delay period $M$ of payments is smaller than the non-instantaneous deterioration period. The retailer can earn the sales revenue of the system by selling products. After selling products, he deposits this revenue in a bank of an interest-bearing account for the favorable stock of the system, but in the case of a shortage period, he can only earn a simple interest as he gets all his revenue at a time, which can be expressed in mathematical form as follows:

The interest earned:

$$
\begin{aligned}
\mathrm{IE}_{1} & =p I_{e} \int_{0}^{t_{2}} \int_{0}^{t} D \mathrm{~d} u \mathrm{~d} t+\frac{p I_{e} D t_{2}}{\delta} \log \left(1+\delta\left(T-t_{2}\right)\right) \\
& =\frac{p I_{e} D t_{2}^{2}}{2}+\frac{p I_{e} D t_{2}}{\delta} \log \left(1+\delta\left(T-t_{2}\right)\right)
\end{aligned}
$$


However, the retailer does not have to pay any interest beyond the permissible period $M$, as the supplier offers this period to him. After this permissible period, the retailer needs to pay the interest, which we can express mathematically,

$$
\begin{aligned}
\mathrm{IC}_{1} & =c I_{c} \int_{M}^{t_{1}} I_{1}(t) \mathrm{d} t+c I_{c} \int_{t_{1}}^{t_{2}} I_{2}(t) \mathrm{d} t \\
& =c I_{c}\left[S\left(t_{1}-M\right)-D \frac{\left(t_{1}^{2}-M^{2}\right)}{2}\right]-\frac{c I_{c} D}{(\theta m(\xi))^{2}}\left[\left(1-e^{\theta m(\xi)\left(t_{2}-t_{1}\right)}\right)+\theta m(\xi)\left(t_{2}-t_{1}\right)\right] .
\end{aligned}
$$

Hereafter, one can write the total profit of the chain as:

$$
\pi^{1}(p, \xi, T)=\frac{X_{11}}{T}
$$

where

$$
\begin{aligned}
X_{11}= & \left(f_{\mathrm{SR}}-\mathrm{OC}-f_{\mathrm{PC}}-f_{\mathrm{HC}}-f_{\mathrm{BC}}-f_{\mathrm{LSC}}-f_{\mathrm{PTC}}+\mathrm{IE}_{1}-\mathrm{IC}_{1}\right) \\
= & p\left[D t_{2}+\frac{D}{\delta}\left\{\log \left(1+\delta\left(T-t_{2}\right)\right)\right\}\right]-K-c\left[D t_{1}+\frac{D}{\theta m(\xi)}\left(e^{\theta m(\xi)\left(t_{2}-t_{1}\right)}-1\right)\right. \\
& \left.+\frac{D}{\delta}\left\{\log \left(1+\delta\left(T-t_{2}\right)\right)\right\}\right]-c_{1}\left[S t_{1}-\frac{D t_{1}^{2}}{2}-\frac{D}{\theta^{2} m(\xi)^{2}}\left(1-e^{\theta m(\xi)\left(t_{2}-t_{1}\right)}+\theta m(\xi)\left(t_{2}-t_{1}\right)\right)\right] \\
& -c_{2}\left(R+\frac{D}{\delta}\left(T-t_{2}\right)\right)-\frac{c_{2} D}{\delta^{2}}\left(1+\delta\left(T-t_{2}\right)\right) \log \left(1+\delta\left(T-t_{2}\right)\right) \\
& -\frac{c_{3} D}{\delta}\left\{\delta\left(T-t_{2}\right)-\log \left(1+\delta\left(T-t_{2}\right)\right)\right\}+\frac{p I_{e} D t_{2}^{2}}{2}+\frac{p I_{e} D t_{2}}{\delta} \log \left(1+\delta\left(T-t_{2}\right)\right) \\
& -\xi T-c I_{c}\left[S\left(t_{1}-M\right)-D \frac{\left(t_{1}^{2}-M^{2}\right)}{2}\right]+\frac{c I_{c} D}{(\theta m(\xi))^{2}}\left[\left(1-e^{\theta m(\xi)\left(t_{2}-t_{1}\right)}\right)+\theta m(\xi)\left(t_{2}-t_{1}\right)\right] .
\end{aligned}
$$

Henceforth, the problem is written as follows:

Problem 3.1. $\pi^{1}(p, \xi, T)=\frac{X_{11}}{T}$.

With condition $0<M \leq t_{1}$.

Case 2. When $t_{1}<M \leq t_{2}$.

For this case, the approvable delay period of payments belongs within the time interval $\left[t_{1}, t_{2}\right]$. Therefore, the retailer can earn interest easily like a similar way of Case 1 from the system, which can be expressed mathematically as:

Interest earned:

$$
\mathrm{IE}_{2}=\mathrm{IE}_{1}=\frac{p I_{e} D t_{2}^{2}}{2}+\frac{p I_{e} D t_{2}}{\delta} \log \left(1+\delta\left(T-t_{2}\right)\right) .
$$

However, the retailer needs to pay interest in this instance, from the delay period $M$ to the end of the positive stock. After a time $t=t_{2}$, he does not need to pay interest as there are no positive stocks. Therefore, the interest paid to the supplier is:

$$
\begin{aligned}
\mathrm{IC}_{2} & =c I_{c} \int_{M}^{t_{2}} I_{2}(t) \mathrm{d} t \\
& =c I_{c}\left[\frac{D}{(\theta m(\xi))^{2}}\left(e^{\theta m(\xi)\left(t_{2}-M\right)}-1\right)-\frac{D\left(t_{2}-M\right)}{\theta m(\xi)}\right] .
\end{aligned}
$$


Thus, the total profit of the system looks like as:

$$
\pi^{2}(p, \xi, T)=\frac{X_{12}}{T}
$$

where,

$$
\begin{aligned}
X_{12}= & \left(f_{\mathrm{SR}}-\mathrm{OC}-f_{\mathrm{PC}}-f_{\mathrm{HC}}-f_{\mathrm{BC}}-f_{\mathrm{LSC}}-f_{\mathrm{PTC}}+\mathrm{IE}_{2}-\mathrm{IC}_{2}\right) \\
= & p\left[D t_{2}+\frac{D}{\delta}\left\{\log \left(1+\delta\left(T-t_{2}\right)\right)\right\}\right]-K-c\left[D t_{1}+\frac{D}{\theta m(\xi)}\left(e^{\theta m(\xi)\left(t_{2}-t_{1}\right)}-1\right)\right. \\
& \left.+\frac{D}{\delta}\left\{\log \left(1+\delta\left(T-t_{2}\right)\right)\right\}\right]-c_{1}\left[S t_{1}-\frac{D t_{1}^{2}}{2}-\frac{D}{\theta^{2} m(\xi)^{2}}\left(1-e^{\theta m(\xi)\left(t_{2}-t_{1}\right)}+\theta m(\xi)\left(t_{2}-t_{1}\right)\right)\right] \\
& -c_{2}\left[\left(R+\frac{D}{\delta}\left(T-t_{2}\right)\right)-\frac{D}{\delta^{2}}\left(1+\delta\left(T-t_{2}\right)\right) \log \left(1+\delta\left(T-t_{2}\right)\right)\right] \\
& -\xi T-\frac{c_{3} D}{\delta}\left\{\delta\left(T-t_{2}\right)-\log \left(1+\delta\left(T-t_{2}\right)\right)\right\}+\frac{p I_{e} D t_{2}^{2}}{2}+\frac{p I_{e} D t_{2}}{\delta} \log \left(1+\delta\left(T-t_{2}\right)\right) \\
& -c I_{c}\left[\frac{D}{(\theta m(\xi))^{2}}\left(e^{\theta m(\xi)\left(t_{2}-M\right)}-1\right)+\frac{D\left(t_{2}-M\right)}{\theta m(\xi)}\right] .
\end{aligned}
$$

Henceforth, the problem is written as follows:

Problem 3.2. $\pi^{2}(p, \xi, T)=\frac{X_{12}}{T}$.

With condition $t_{1}<M \leq t_{2}$.

Case 3. When $t_{2}<M \leq T$.

Here, the total earning of interest is similar to our previous Case 1, therefore.

The interest earned in this case is also,

$$
\mathrm{IE}_{3}=\mathrm{IE}_{1}=\frac{p I_{e} D t_{2}^{2}}{2}+\frac{p I_{e} D t_{2}}{\delta} \log \left(1+\delta\left(T-t_{2}\right)\right) .
$$

As it is clear from the condition that the length of the payment system's approvable delay period is larger than the excellent stock time. Therefore, here the interest that needs to be paid by the retailer to the supplier is zero as there is no stock in the hand of the retailer. Hereafter, the total profit of the system for this case is

where

$$
\pi^{3}(p, T, \xi)=\frac{X_{13}}{T}
$$

$$
\begin{aligned}
X_{13}= & \left(f_{\mathrm{SR}}-\mathrm{OC}-f_{\mathrm{PC}}-f_{\mathrm{HC}}-f_{\mathrm{BC}}-f_{\mathrm{LSC}}-f_{\mathrm{PTC}}+\mathrm{IE}_{3}\right) \\
= & p\left[D t_{2}+\frac{D}{\delta}\left(\log \left(1+\delta\left(T-t_{2}\right)\right)\right)\right]-K-c\left[D t_{1}+\frac{D}{\theta m(\xi)}\left(e^{\theta m(\xi)\left(t_{2}-t_{1}\right)}-1\right)\right. \\
& \left.+\frac{D}{\delta}\left\{\log \left(1+\delta\left(T-t_{2}\right)\right)\right\}\right] \\
& -c_{1}\left[S t_{1}-\frac{D t_{1}^{2}}{2}-\frac{D}{\theta^{2} m(\xi)^{2}}\left(1-e^{\theta m(\xi)\left(t_{2}-t_{1}\right)}+\theta m(\xi)\left(t_{2}-t_{1}\right)\right)\right] \\
& -c_{2}\left[\left(R+\frac{D}{\delta}\left(T-t_{2}\right)\right)-\frac{D}{\delta}\left(1+\delta\left(T-t_{2}\right)\right) \log \left(1+\delta\left(T-t_{2}\right)\right)\right] \\
& -\frac{c_{3} D}{\delta}\left\{\delta\left(T-t_{2}\right)-\log \left(1+\delta\left(T-t_{2}\right)\right)\right\}-\xi T+\frac{p I_{e} D t_{2}^{2}}{2}+\frac{p I_{e} D t_{2}}{\delta} \log \left(1+\delta\left(T-t_{2}\right)\right) .
\end{aligned}
$$


Henceforth, the problem is written as follows:

Problem 3.3. $\pi(p, T, \xi)=\frac{X_{13}}{T}$.

With condition $t_{2}<M \leq T$.

\section{TheOretical DeRIVATION AND Discussion}

To derive the concavity of the profit function in terms of decision variables, one needs to show that it satisfies the necessary conditions for those decision variables. For this, it is needed to differentiate equation (3.23) concerning decision variables $p, \xi, T$.

Therefore, one can write

$$
\frac{\partial \pi^{3}(p, T, \xi)}{\partial p}=\frac{\partial}{\partial p}\left(\frac{X_{13}}{T}\right)
$$

Now to satisfy the necessary condition, putting $\frac{\partial \pi^{3}(p, T, \xi)}{\partial p}=0$ means,

$$
\left[\begin{array}{c}
(a-2 b p)\left[\left(t_{2}+\frac{1}{\delta}\left(\log \left(1+\delta\left(T-t_{2}\right)\right)\right)\right)+\frac{1}{2}\left(I_{e} t_{2}^{2}+\frac{I_{e} t_{2}}{\delta} \log \left(1+\delta\left(T-t_{2}\right)\right)\right)\right] \\
\quad+c\left[b t_{1}+\frac{b}{\theta m(\xi)}\left(e^{\theta m(\xi)\left(t_{2}-t_{1}\right)}-1\right)+\frac{b}{\delta}\left\{\log \left(1+\delta\left(T-t_{2}\right)\right)\right\}\right] \\
\quad-c_{1}\left[\frac{b t_{1}^{2}}{2}+\frac{b}{\theta^{2} m(\xi)^{2}}\left(\begin{array}{c}
1-e^{\theta m(\xi)\left(t_{2}-t_{1}\right)} \\
+\theta m(\xi)\left(t_{2}-t_{1}\right)
\end{array}\right)\right] \\
\quad+c_{2}\left[\left(\frac{b}{\delta} \log \left(T-t_{2}\right)+\frac{b}{\delta}\left(T-t_{2}\right)\right)+\frac{b}{\delta^{2}}\left(1+\delta\left(T-t_{2}\right)\right) \log \left(1+\delta\left(T-t_{2}\right)\right)\right] \\
\quad+\frac{c_{3} b}{\delta}\left\{\delta\left(T-t_{2}\right)-\log \left(1+\delta\left(T-t_{2}\right)\right)\right\}
\end{array}\right]=0 .
$$

Similarly,

$$
\left[\begin{array}{c}
(p-c)\left(\frac{D}{\left(\log \left(1+\delta\left(T-t_{2}\right)\right)\right)}\right)+c_{2}\left[\left(\frac{D}{\left(1+\delta\left(T-t_{2}\right)\right)}+\frac{1}{\delta}\right)-\frac{1}{\delta}\left(1+\log \left(1+\delta\left(T-t_{2}\right)\right)\right)\right] \\
+\frac{c_{3} D \delta\left(T-t_{2}\right)}{1+\delta\left(T-t_{2}\right)}-\xi+p I_{e} D t_{2}-\frac{1}{T^{2}} \pi^{3}(p, \xi, T)
\end{array}\right]=0
$$

and,

$$
\frac{1}{T}\left[\begin{array}{l}
c \frac{D}{\theta m(\xi)}\left[\left(e^{\theta m(\xi)\left(t_{2}-t_{1}\right)} \theta\left(t_{2}-t_{1}\right) a_{1} e^{-a_{1} \xi}\right)+\frac{1}{m(\xi)}\left(e^{\theta m(\xi)\left(t_{2}-t_{1}\right)}-1\right)\right]-c_{1} \frac{D}{\theta^{2} m(\xi)^{2}} \\
{\left[\left(e^{\theta m(\xi)\left(t_{2}-t_{1}\right)} \theta\left(t_{2}-t_{1}\right) a_{1} e^{-a_{1} \xi}+\theta a_{1} e^{-a_{1} \xi}\left(t_{2}-t_{1}\right)\right)+\frac{1}{m(\xi)}\left(1-e^{\theta m(\xi)\left(t_{2}-t_{1}\right)}+\theta m(\xi)\left(t_{2}-t_{1}\right)\right)\right]-T}
\end{array}\right]
$$

$$
=0 .
$$

After simultaneously solving equations (4.1)-(4.3), one gets the optimal solution $\left(p^{*}, \xi^{*}, T^{*}\right)$. Now, the objective function $\pi^{i}(p, \xi, T)_{i=1,2,3}$ is exceedingly non-linear. Thus, it is impossible to derive the total profit of the chain jointly concave for the decision variables $p, \xi$ and $T$. Therefore, by dint of some conditions, this section shows the theoretical derivation of the profit function. For the proof, some results of Cambini and Martein [4], Schaible [36], and Dye [9] are directly used in this section.

Lemma 4.1. If $\mu_{1}(x)$ is non-negative, differentiable, and (strictly) concave, and $\mu_{2}(x)$ is positive, differentiable, and convex, then the real-value function $\mu(x)=\frac{\mu_{1}(x)}{\mu_{2}(x)}$ is (strictly) pseudo-concave.

Proof. See Cambini and Martein [4] for details.

Consequently, for any particular $p$ and $\xi$, there occurs a distinctive global optimum solution $T_{i}^{*}$ so that the objective function $\pi^{i}(p, \xi, T)$, for $i=1,2$, and 3 is maximized.

Now, one can maximize $\pi^{i}(p, \xi, T)$, for $i=1,2$, and 3 disjointedly. Through using Lemma 4.1, one easily can get the subsequent results. 
Theorem 4.2. For any given $p$ and $\xi$, equation (3.23) entails maximum profit in $T$, giving a unique extreme result $T^{*}$.

Proof. When $i=3$, from equation (3.23), one can define

$$
\mu_{1}(T)=\left[\begin{array}{c}
p\left[D t_{2}+\frac{D}{\delta}\left(\log \left(1+\delta\left(T-t_{2}\right)\right)\right)\right]-K-c\left[D t_{1}+\frac{D}{\theta m(\xi)}\left(e^{\theta m(\xi)\left(t_{2}-t_{1}\right)}-1\right)+\frac{D}{\delta}\left\{\log \left(1+\delta\left(T-t_{2}\right)\right)\right\}\right] \\
-c_{1}\left[S t_{1}-\frac{D t_{1}^{2}}{2}-\frac{D}{\theta m^{2}(\xi)^{2}}\left(1-e^{\theta m(\xi)\left(t_{2}-t_{1}\right)}+\theta m(\xi)\left(t_{2}-t_{1}\right)\right)\right] \\
-c_{2}\left[\left(R+\frac{D}{\delta}\left(T-t_{2}\right)\right)-\frac{D}{\delta^{2}}\left(1+\delta\left(T-t_{2}\right)\right) \log \left(1+\delta\left(T-t_{2}\right)\right)\right] \\
-\frac{c_{3} D}{\delta}\left\{\delta\left(T-t_{2}\right)-\log \left(1+\delta\left(T-t_{2}\right)\right)\right\}-\xi T+\frac{p I_{e} D t_{2}^{2}}{2}+\frac{p I_{e} D t_{2}}{\delta} \log \left(1+\delta\left(T-t_{2}\right)\right)
\end{array}\right]
$$

Now, differentiate $\mu_{1}(T)$ regarding $T$ for one time.

$$
\mu_{1}^{\prime}(T)=\left[\begin{array}{l}
p\left(\frac{D}{\delta} \frac{\delta}{\left(1+\delta\left(T-t_{2}\right)\right)}\right)-c\left(\frac{D}{\delta} \frac{\delta}{\left(1+\delta\left(T-t_{2}\right)\right)}\right)-\frac{c_{3} D}{\delta}\left\{\delta-\frac{\delta}{\left(1+\delta\left(T-t_{2}\right)\right)}\right\} \\
\quad-c_{2}\left[\left(\frac{\partial R}{\partial T}+\frac{D}{\delta}\right)-\frac{A^{\gamma} D}{\delta^{2}}\left(\left(1+\delta\left(T-t_{2}\right)\right) \frac{\delta}{\left(1+\delta\left(T-t_{2}\right)\right)}+\delta \log \left(1+\delta\left(T-t_{2}\right)\right)\right)\right] \\
\quad \xi+\frac{p I_{e} D t_{2}}{\delta} \frac{\delta}{\left(1+\delta\left(T-t_{2}\right)\right)}
\end{array}\right] .
$$

In the same way, the second-order derivative respecting decision variable $T$ is:

$$
\begin{aligned}
\mu_{2}^{\prime \prime}(T) & =\left[\begin{array}{c}
\left.(c-p)\left(\frac{\delta D}{\left(1+\delta\left(T-t_{2}\right)\right)^{2}}\right)-c_{2}\left\{\left(\frac{\partial^{2} R}{\partial T^{2}}\right)-\left(\frac{D}{\left(1+\delta\left(T-t_{2}\right)\right)}\right)\right\}-\frac{c_{3} D}{\delta}\left\{\frac{\delta^{2}}{\left(1+\delta\left(T-t_{2}\right)\right)^{2}}\right\}\right] \\
-\frac{\delta p I_{e} D t_{2}}{\left(1+\delta\left(T-t_{2}\right)\right)^{2}}
\end{array}\right] \\
& =-\left[\left(p-c+c_{3}\right) \Psi_{1}+c_{2}\left(\Psi_{1}-\frac{\sqrt{D \delta}}{\sqrt{\psi_{1}}}\right)+p I_{e} t_{2} \Psi_{1}\right]<0
\end{aligned}
$$

where $\Psi_{1}=\frac{\delta D}{\left(1+\delta\left(T-t_{2}\right)\right)^{2}}$ and $D=A^{\gamma}(a-b p)$.

Since the double derivative $\mu_{1}(T)$ is negative. Therefore, the function $\mu_{1}(T)$ shows its negativity together with concavity and the nature of differentiability. Furthermore, $\mu_{2}(T)=T$ also exhibits its positivity with convexity, and it is also differentiable concerning $T$. As a result, one can conclude that the function $\pi^{i}(p, \xi, T)$, is a strictly pseudo-concave in $T$, and hereafter it entails an individual optimum result $T^{*}$.

Theorem 4.3. For any given $\xi$ and $T$, equation (3.23) entails maximum profit in $p$, and hence it gives a unique extreme result $p^{*}$.

Proof. The proof is omitted owing to the similar characteristics to Theorem 4.2.

Theorem 4.4. For any given $p$ and $T$, equation (3.23) entails maximum profit in $\xi$, and hence it gives a unique extreme result $\xi^{*}$.

Proof. The proof is omitted owing to similar characteristics to Theorem 4.2.

Theorem 4.5. For any given $\xi$, equation (3.23) entails maximum profit in $p$ and $T$; hence, it gives a unique extreme result at $\left(p^{*}, T^{*}\right)$.

Proof. When, $i=3$, then from equation (3.23), it gives

$$
\mu_{1}(p, T)=\left[\begin{array}{c}
p\left[D t_{2}+\frac{D}{\delta}\left(\log \left(1+\delta\left(T-t_{2}\right)\right)\right)\right]-K \\
-c\left[D t_{1}+\frac{D}{\theta m(\xi)}\left(e^{\theta m(\xi)\left(t_{2}-t_{1}\right)}-1\right)+\frac{D}{\delta}\left\{\log \left(1+\delta\left(T-t_{2}\right)\right)\right\}\right] \\
-c_{1}\left[S t_{1}-\frac{D t_{1}^{2}}{2}-\frac{D}{\theta^{2} m(\xi)^{2}}\left(1-e^{\theta m(\xi)\left(t_{2}-t_{1}\right)}+\theta m(\xi)\left(t_{2}-t_{1}\right)\right)\right] \\
-c_{2}\left[\left(R+\frac{D}{\delta^{2}}\left(T-t_{2}\right)\right)-\frac{D}{\delta}\left(1+\delta\left(T-t_{2}\right)\right) \log \left(1+\delta\left(T-t_{2}\right)\right)\right] \\
-\frac{c_{3} D}{\delta}\left\{\delta\left(T-t_{2}\right)-\log \left(1+\delta\left(T-t_{2}\right)\right)\right\}-\xi T+\frac{p I_{e} D t_{2}^{2}}{2}+\frac{p I_{e} D t_{2}}{\delta} \log \left(1+\delta\left(T-t_{2}\right)\right)
\end{array}\right]
$$




$$
\mu_{2}(p, T)=T>0 .
$$

Agreeing to the outcomes of Cambini and Martein [4], Schaible [36] and Dye [9], it is obligatory to illustrate that the function $\mu_{1}(p, T)$ is negative, differentiable, and (strictly) joint concave function relating variables $p$ and $T$. To produce the Hessian matrix respecting variables $p$ and $T$ for $\mu_{1}(p, T)$, it is necessary to compute second-order partial derivatives.

$$
\begin{aligned}
& \frac{\partial^{2} \mu_{1}(p, T)}{\partial p^{2}}=\left[p-b A^{\gamma} t_{2}\left(1-t_{2}\right)-\log \left(1+\delta\left(T-t_{2}\right)\right)\left(\frac{2 I_{e} b A^{\gamma} t_{2}}{\delta}+\frac{b A^{\gamma}}{\delta}\right)\right] \\
& \frac{\partial^{2} \mu_{1}(p, T)}{\partial T^{2}}=-\frac{\delta A^{\gamma}(a-b p)}{\left(1+\delta\left(T-t_{2}\right)\right)^{2}}\left[(p-c)+c_{2}\left\{1-\frac{\left(1+\delta\left(T-t_{2}\right)\right)}{\delta}\right\}+c_{3}+p I_{e} t_{2}\right] \\
& \frac{\partial^{2} \mu_{1}(p, T)}{\partial p \partial T}=\frac{A^{\gamma}}{\left(1+\delta\left(T-t_{2}\right)\right)}\left[\begin{array}{c}
\left.b(c-p)+(a-b p)-c_{2} b\left(\frac{1}{\delta} \log \left(1+\delta\left(T-t_{2}\right)\right)\left(1+\delta\left(T-t_{2}\right)\right)-1\right)\right] . \\
+c_{3} b \delta\left(T-t_{2}\right)+I_{e}(a-b p) t_{2}-p I_{e} b t_{2}
\end{array}\right] .
\end{aligned}
$$

Thus, one can write the Hessian matrix for $\mu_{1}(p, T)$ function is:

$$
H_{i j}=\left[\begin{array}{ll}
\frac{\partial^{2} \mu_{1}}{\partial^{2} p} & \frac{\partial^{2} \mu_{1}}{\partial p \partial T} \\
\frac{\partial^{2} \mu_{1}}{\partial T \partial p} & \frac{\partial^{2} \mu_{1}}{\partial T^{2}}
\end{array}\right] .
$$

Now, the calculation of the first principal minor of the hessian matrix $H_{11}$ and which is

$$
\left|H_{11}\right|=\frac{\partial^{2} \mu_{1}(p, T)}{\partial p^{2}}=-\left[b A^{\gamma} 2 t_{2}\left(1-t_{2}\right)+\log \left(1+\delta\left(T-t_{2}\right)\right)\left(\frac{2 I_{e} b A^{\gamma} t_{2}}{\delta}+\frac{b A^{\gamma}}{\delta}\right)-p\right] .
$$

It has been undoubtedly negative.

Consequently, the second principal minor of the hessian matrix $H_{22}$ and which is

$$
\begin{aligned}
& \left|H_{22}\right|=\frac{\partial^{2} \mu_{1}(p, T)}{\partial p^{2}} \frac{\partial^{2} \mu_{1}(p, T)}{\partial T^{2}}-\left(\frac{\partial^{2} \mu_{1}(p, T)}{\partial p \partial T}\right)^{2}
\end{aligned}
$$

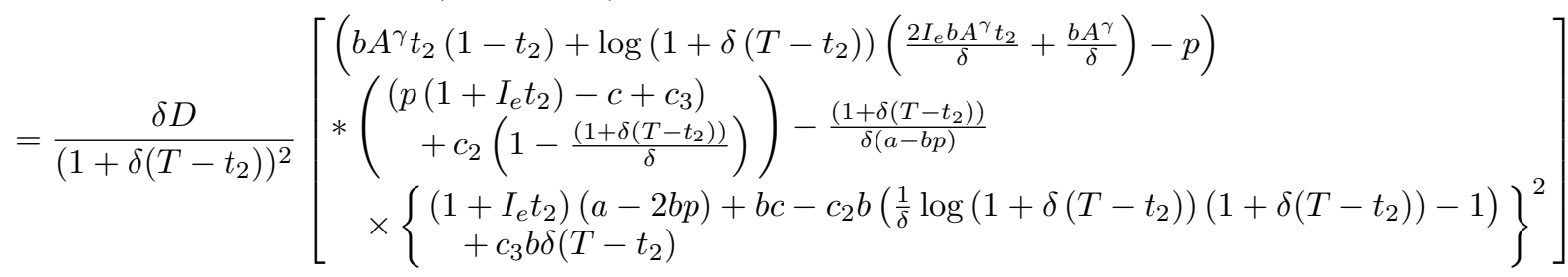

$$
\begin{aligned}
& =\frac{D \chi_{1}^{2}}{\delta}\left[\left(\gamma_{2}+\log \frac{\delta}{\chi_{1}} \gamma_{3}-p\right) *\left(\left(p \gamma_{1}-c+c_{3}\right)+c_{2}\left(1-\frac{1}{\chi_{1}}\right)\right)\right. \\
& \left.-\frac{1}{\chi_{1}(a-b p)}\left(\begin{array}{c}
\gamma_{1}(a-2 b p)+b c-c_{2} b\left(\frac{1}{\delta} \log \chi_{1}^{2}-1\right) \\
+c_{3} b\left(\frac{\delta}{\chi_{1}}-1\right)
\end{array}\right)^{2}\right]
\end{aligned}
$$

where, $\frac{\delta}{\left(1+\delta\left(T-t_{2}\right)\right)}=\chi_{1},\left(1+I_{e} t_{2}\right)=\gamma_{1}, b A^{\gamma} t_{2}\left(1-t_{2}\right)=\gamma_{2},\left(\frac{2 I_{e} b A^{\gamma} t_{2}}{\delta}+\frac{b A^{\gamma}}{\delta}\right)=\gamma_{3}$.

Since all the terms $\chi_{1}, \gamma_{1}, \gamma_{2}, \gamma_{3}$ are positive while it is also assumed that within the complete cycle length of the chain, per unit lost sale cost is always larger than the purchase cost of the chain. Thus, one can easily clinch; the second principal minor $\left|H_{22}\right|$ is positive, and consequently, the Hessian matrix $H_{i j}$ for this problem is positive.

In the meantime, for the function $\mu_{1}(p, T)$, the negativity showed by its first principal minor and positively behaved by its second principal minors of the Hessian matrix. Thus the situation is treating as the negative 
definite matrix. Consequently, the function $\mu_{1}(p, T)$ shows its negativity and concavity and the nature of differentiability regarding variables $p$ and $T$. Furthermore, previously, it is observed that the function $\mu_{2}(p, T)=T$ shows its positivity characteristics with differentiability. Moreover, it is also convex. Therefore, $\pi^{i}(p, \xi, T)$, is pseudo-concave in $p$ and $T$ per unit time, and it takes merely a single maximum value. As a result, the objective function $\pi^{i}(p, \xi, T)$, accomplishes its global maximum value in those optimal points $\left(p^{*}, T^{*}\right)$.

Theorem 4.6. For any given $T$, equation (3.23) entails maximum profit in $p$, and $\xi$ hence it gives a unique extreme result at $\left(p^{*}, \xi^{*}\right)$.

Proof. The proof is omitted owing to the similar characteristics to Theorem 4.5.

Theorem 4.7. For any given p, equation (3.23) entails maximum profit in $\xi$ and $T$; hence it gives a unique extreme result at $\left(\xi^{*}, T^{*}\right)$.

Proof. The proof is omitted owing to the similar characteristics to Theorem 4.5.

\section{Special CASES}

(I) When the backlogging parameter tends to infinite, i.e., $\delta \rightarrow \infty$ (i.e., no shortages), at that time, the equation of shortages from the model will be omitted. As a result, no shortages will appear in the proposed economic order quantity model.

(II) If one puts $\gamma=0$ that is the frequency of advertisement becomes 1 (one), then the anticipated model will be concentrated to a model with price dependent demand, which is similar to the model of Zhang et al. [50] and Liu et al. [22].

(III) If non-deterioration period, $t_{1}=0$ together with $\gamma=0$ and $\delta \rightarrow \infty$, i.e., without shortages, then the projected model degenerates to the Mishra et al. [29].

(IV) When the backlogging parameter tends to zero, i.e., $\delta \rightarrow 0$ at that time, the recommended model moderates to a completely backlogged model.

(V) If non-deteriorating time is $t_{1}=0$ and the demand is fixed, then the anticipated model moderates to Dye et al. [10].

\section{NuMERICAL ILLUSTRATIONS}

In this section, in Section 6.1, some numerical examples are provided to validate the model numerically. In Section 6.2, a comparison table among the related research to the proposed model with a pictorial view is given in the later section.

\subsection{Numerical examples}

Here, it discussed the solution of the proposed inventory model. This proposed model is more applicable for declining products resembling vegetables, fruit, and sweets. The demand for these products during any season gets higher, correspondingly relying upon the sales price. Initially, there will be no deterioration for some time after it starts; thus, the stock will be depleted. A well-known instance of the proposed model is credit card supply by banks to their customers. This example is reasonable in favor of the proposed model. Using credit cards, retailers buy products and run their businesses.

Several examples are solved by Lingo 15 software to illustrate the inventory model. Some revised data is presented in Example 6.1 from Dye et al. [10] to demonstrate the model as follows: 
TABLE 3. Outcomes of the proposed study.

\begin{tabular}{llllllll}
\hline \hline \multirow{2}{*}{ Examples } & \multicolumn{6}{c}{ Results } \\
\cline { 2 - 8 } & Circumstance & $S^{*}$ & $R^{*}$ & $p^{*}$ & $\xi^{*}$ & $T^{*}$ & $\pi^{2}(p, \xi, T)$ \\
\hline Case 1 & $0<M \leq t_{1}$ & 184.50 & 29.89 & 39.90 & 0.37 & 1.83 & 1295.50 \\
Case 2 & $t_{1}<M \leq t_{2}$ & 288.85 & 29.44 & 41.27 & 0.47 & 2.58 & 1308.57 \\
Case 3 & $t_{2}<M \leq T$ & 267.73 & 33.86 & 40.96 & 0.45 & 2.50 & 1324.80 \\
\hline
\end{tabular}

\section{Example 6.1.}

\begin{tabular}{llll}
\hline Cost components & Value & Cost components & Value \\
\hline Advertisement frequency $(A)$ & $1.2 /$ cycle & $\begin{array}{l}\text { The rate at which products dete- } \\
\text { riorate is, }(\theta)\end{array}$ & $0.5 /$ unit \\
\hline Cost of order confirmation $(K)$ & $\$ 1500 /$ unit & $\begin{array}{l}\text { Time from which deterioration } \\
\text { will begin is }\left(t_{1}\right)\end{array}$ & 0.03 year \\
\hline $\begin{array}{l}\text { Holding cost of diverse products } \\
\left(C_{1}\right)\end{array}$ & $\$ 5 /$ unit & Backlogging factor, $(\delta)$ & 1.5 \\
\hline $\begin{array}{l}\text { Due to backorder of stock out } \\
\text { products cost is }\left(C_{2}\right)\end{array}$ & $\$ 5 /$ unit & $\begin{array}{l}\text { Length of the permissible delay } \\
\text { time frame that the supplier } \\
\text { offers }(M)\end{array}$ & 0.01 year \\
$\begin{array}{l}\text { Cost of lost sale due to the end } \\
\text { of the stock is, }\left(C_{3}\right)\end{array}$ & $\$ 27 /$ unit & Interest earned, $\left(I_{e}\right)$ & $\$ 0.12$ \\
\hline $\begin{array}{l}\text { Cost of purchasing various items } \\
\text { is, }(C)\end{array}$ & $\$ 8 /$ unit & Interest charged, $\left(I_{e}\right)$ & $\$ 0.06$ \\
\hline $\begin{array}{l}\text { Elasticity parameter of adver- } \\
\text { tisement, }(\gamma)\end{array}$ & 0.02 & $\begin{array}{l}\text { Shape parameter for the price, } \\
(a)\end{array}$ & 300 \\
\hline Price coefficient, $(b)$ & $\$ 5 /$ unit & Preservation coefficient, $\left(a_{1}\right)$ & $\$ 0.8 /$ unit \\
\hline
\end{tabular}

Example 6.2. Let us keep all quantities the same except for $M=0.3$ year.

Example 6.3. Let us keep all quantities the same except for $M=2.5$ year.

Consequently, Figures 3-5 display some concave graphs of the profit function (winner Case 3) relating to decision variables (Tab. 3 ).

Example 6.4. The same parametric values used for this example, which were earlier used by Zhang et al. [50] in his model as:

$$
\begin{aligned}
& \text { OC }=k=\$ 80 / \text { per order } ; a=\alpha=100 ; b=\beta=5 ; c_{1}=h=\$ 1 / \text { per unit } / \text { per month; } \\
& a_{1}=\gamma=0.05 ; c=\$ 5 / \text { per unit; } \theta=0.5 .
\end{aligned}
$$

As the trade-credit policy is absent in Zhang et al.'s [50] model, so it is considered $M=0, I_{e}=0$, and $\gamma=0$.

Optimum result: $p^{*}=13.22, \xi^{*}=12.19, T^{*}=1.58, \pi^{*}(p, \xi, T)=166.71$, whereas with the same values, Zhang et al.'s [50] model is 153.82 (Tab. 4).

Observation. When the accrued interest values are $I_{e}=0,0.06,0.08$, then one can observe that by the expansion of the trade-credit period, the gross profit is diminished. The retailer desires to sell more products to expand its profit as the trade-credit period, and sales prices rise. However, as the total cycle length increases, the retailer must store the products longer and spend more on preservation technology to protect them while storing the products. 


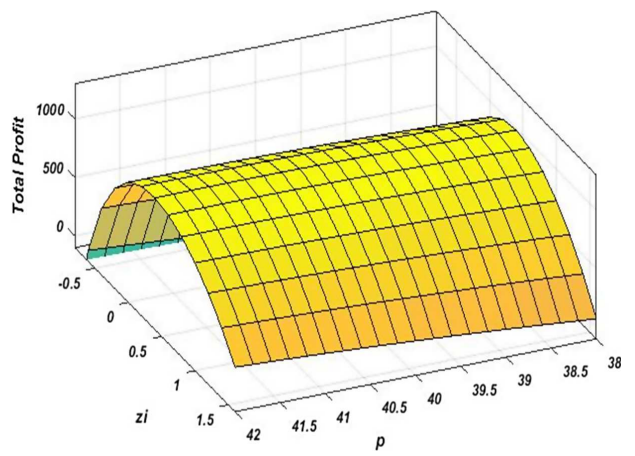

FiguRE 3. The profit function versus the investment in preservation technology and the optimum selling price.

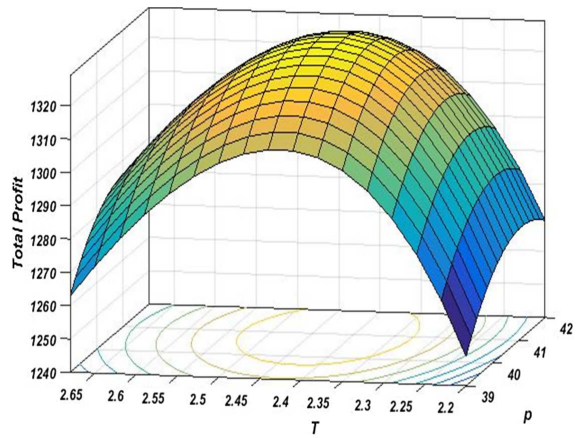

Figure 4 . The profit function versus the cycle length and the optimum selling price.

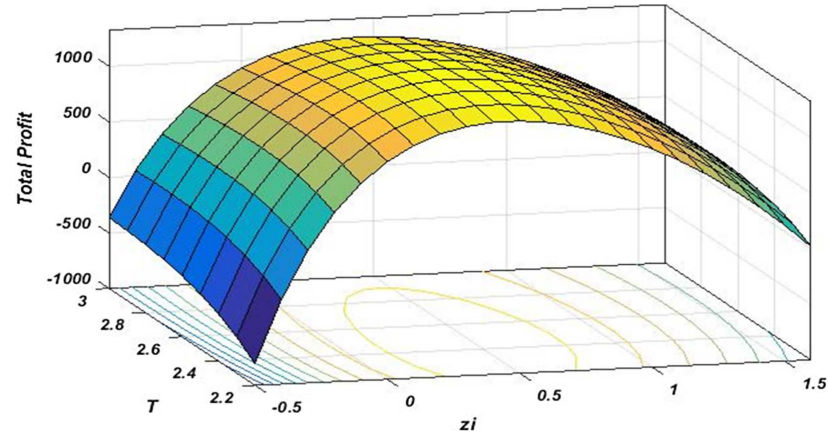

FIgURE 5. The profit function versus the investment on preservation technology and the cycle length.

Example 6.5. For this numerical illustration, all the data are hired from Dye et al. [10] as

$p=\$ 35 /$ per unit; $c_{2}=\$ 4 /$ per unit $/$ per year; $c=\$ 20 /$ per order; $K=\$ 120 /$ per order;

$c_{1}=\$ 3 /$ per unit $/$ per year; $D=\$ 1000 /$ per year; $c_{3}=\$ 5 /$ per unit; $t_{1}=0 ; \delta=2 ; a_{1}=0.01$;

$\theta(t)=0.2+0.1 t$. 
TABLE 4. Results intended aimed at numerous values of $M$ and $I_{e}$.

\begin{tabular}{llllll}
\hline \hline$M$ & $I_{e}$ & $p^{*}$ & $\xi^{*}$ & $T^{*}$ & $\pi^{*}(p, \xi, T)$ \\
\hline 0 & 0 & 13.22 & 12.19 & 1.58 & 166.71 \\
\hline 2.5 & 0 & 13.65 & 13.60 & 2.50 & 155.75 \\
& 0.06 & 13.39 & 13.63 & 2.50 & 188.60 \\
& 0.08 & 13.31 & 13.64 & 2.50 & 199.69 \\
\hline 3 & 0 & 13.89 & 14.37 & 3.00 & 144.85 \\
& 0.06 & 13.57 & 14.41 & 3.00 & 183.57 \\
& 0.08 & 13.48 & 14.42 & 3.00 & 196.71 \\
\hline
\end{tabular}

TABLE 5. Outcomes for various values of $M$ and $I_{e}$.

\begin{tabular}{lllllll}
\hline \hline$M$ & $I_{e}$ & \begin{tabular}{l} 
Is $t_{2}<$ \\
$M \leq$ \\
\\
\multicolumn{7}{c}{ Satisfied? }
\end{tabular} & $p^{*}$ & $\xi^{*}$ & $T^{*}$ & $\pi^{*}(p, \xi, T)$ \\
\hline \multirow{2}{*}{2.5} & 0 & No & 35.00 & 73.62 & 2.53 & 11162.31 \\
& 0.06 & No & 35.00 & 79.20 & 2.89 & 13885.10 \\
& 0.08 & No & 35.00 & 79.22 & 2.89 & 14816.65 \\
\hline 3.2 & 0 & Yes & 35.00 & 83.20 & 3.20 & 10958.48 \\
& 0.06 & Yes & 35.00 & 89.16 & 3.52 & 14076.86 \\
& 0.08 & Yes & 35.00 & 90.71 & 3.62 & 15251.42 \\
\hline 4.5 & 0 & Yes & 35.00 & 100.12 & 4.50 & 9769.280 \\
& 0.06 & Yes & 35.00 & 103.40 & 4.50 & 13755.44 \\
& 0.08 & Yes & 35.00 & 104.12 & 4.50 & 15177.86 \\
\hline 26 & 0 & Yes & 35.00 & - & - & Non-optimal \\
& 0.06 & Yes & 35.00 & 244.00 & 26.00 & 116.78 \\
& 0.08 & Yes & 35.00 & 255.46 & 26.00 & 1060.78 \\
\hline
\end{tabular}

Notes. N.B. the sign (-) use in Table 5, for non-optimal solution.

Moreover, in the absence of trade-credit and interest earn with $\gamma=0$ for the proposed model, then this result is indistinguishable from the model of Dye et al. [10], and the optimum value of the proposed model is 11908.4, whereas, from Dye's model, the value is 13919.3 .

Alternatively, with the presence of trade-credit as $M=3.2$ year; $I_{e}=0.08$; in the proposed model, the optimum solution is

$$
p^{*}=35, \xi^{*}=90.71, T^{*}=3.62, \pi^{*}\left(p^{*}, \xi^{*}, T^{*}\right)=15251.42 .
$$

One cannot take the values of $M$, which will not satisfy the condition $t_{2}<M \leq T$.

$3.2 \leq M \leq 3.5$, after 3.5 , the total profit will decrease and, up to 26 , it will decrease, and after that, the model will give a non-optimal solution.

Observation. It turns out that, once $I_{e}=0$, the gross profit starts to fall with the expansion of the trade-credit approach. Likewise, it occurs while the accrued interest rate is $I_{e}=0.06$ and 0.08 .

One can see from the table that the length of the total cycle will rise by extending the period of trade-credit; consequently, the retailer needs to protect the item for a long. Accordingly, the retailer has to invest further cash into PT, which will lessen the gross profit. It is further noted that the benefits of a trade-credit strategy become the retailer's burdensome after some time.

Example 6.6. When the deterioration rate is not constant. 
TABLE 6. Results of numerous values of $\alpha$ and $\beta$ for $M=3.2$.

\begin{tabular}{llllll}
\hline \hline$\alpha$ & $\beta$ & $p^{*}$ & $\xi^{*}$ & $T^{*}$ & $\pi^{*}(p, \xi, T)$ \\
\hline \multirow{2}{*}{0.02} & 2.2 & 47.15 & 0.02 & 4.08 & 390.42 \\
& 2.4 & 45.33 & 0.17 & 3.84 & 633.62 \\
& 2.6 & 43.91 & 0.31 & 3.65 & 858.27 \\
\hline 0.04 & 2.2 & 43.77 & 0.29 & 3.46 & 895.44 \\
& 2.4 & 42.56 & 0.46 & 3.34 & 1112.59 \\
& 2.6 & 41.62 & 0.62 & 3.24 & 1297.47 \\
\hline 0.06 & 2.2 & 42.25 & 0.49 & 3.23 & 1178.09 \\
& 2.4 & 41.33 & 0.66 & 3.15 & 1362.25 \\
& 2.6 & 40.62 & 0.84 & 3.07 & 1512.67 \\
\hline
\end{tabular}

Problem 6.7. When the deterioration rate follows a Weibull distribution.

Compelling all values as the same as Example 6.3, excluding the deterioration rate, the Weibull distribution deterioration is appropriate to use while fresh lifespan is negligible $t_{1}(>0)$, especially when there is no rapid deterioration available for the anticipated model. For information, one can refer to Begum et al.'s [3] model. Here, the rate of deterioration is used same as Shah et al. [37] as $\theta(t)=\alpha \beta(t-\gamma)^{\beta-1}$. Here in this paper $\gamma=t_{1}$ (deterioration free time). If $\alpha=0.04 ; \beta=2.4 ; \gamma=0.3$, the optimal solution is $p^{*}=42.56, \xi^{*}=0.46, T^{*}=$ $3.34, \pi^{*}(p, \xi, T)=1112.59$.

One can obtain the following remarks from Table 6 :

\section{Observation 1}

Once the values of $\alpha$ are fixed, it can be noted that with the rise of the value, $\beta$ the total profit is increased. It also detected that when the selling price is high, customers do not wish to buy products. Thus the total profit would decrease. Consequently, retailers can attract more customers when the selling price becomes low, increasing their total profits. However, with the growth of the value of $\alpha$ the total profit is improved.

\section{Observation 2}

While the values $\alpha$ are fixed and the increase of $\beta$, it is noted that the total cost of preservation technology is increased. Consequently, the total profit will upsurge because of investing more money to preserve products. Investing in preservation technology reduces deterioration. The same thing happens when the value $\alpha$ is increased.

\section{Observation 3}

If $\alpha$ is fixed, then with the increase in the value of $\beta$ it can be detected that the total cycle length is decreased, and accordingly, the total profit is increased. Consequently, with the intensification of both $\alpha$ and $\beta$ the entire cycle length decreased, which would imply increase profits.

Problem 6.8. When the deterioration rate is variable.

For this example, it is captivating all parameters similar to Example 6.3, excluding the deterioration rate. For this case, the deterioration rate $\theta(t)=0.2+0.1 t$ that used by Dye et al. [10] is adapted to our model. After the implementation of this deterioration rate in the recommended model, the optimum solution is $p^{*}=$ $42.27566, \xi^{*}=0.4355893, T^{*}=2.867090, \pi^{*}(p, \xi, T)=1178.138$.

\subsection{Comparison of results}

This section provides a comparison table with some related research and our proposed model (winner Case 3) presented in the following Table 7. 
TABLE 7. Result comparison.

\begin{tabular}{|c|c|c|c|c|}
\hline Condition & $\begin{array}{l}\text { Profit of Zhang } \\
\text { et al. [50] }\end{array}$ & $\begin{array}{l}\text { Profit of proposed } \\
\text { model with the same } \\
\text { data as Zhang et al. } \\
{[50]}\end{array}$ & $\begin{array}{l}\text { Profit of Dye } \\
\text { et al. [10] }\end{array}$ & $\begin{array}{l}\text { Profit of proposed } \\
\text { model with the } \\
\text { same data as Dye } \\
\text { et al. }[10]\end{array}$ \\
\hline $\begin{array}{l}\text { When trade-credit } \\
\text { absent }\end{array}$ & 153.82 & 166.71 & 11908.4 & 13919.3 \\
\hline With trade-credit & No trade-credit & $\begin{array}{l}199.69 \\
\left(M=2.5, I_{e}=0.08\right)\end{array}$ & No trade-credit & $\begin{array}{l}15251.42 \\
\left(M=3.2, I_{e}=0.08\right)\end{array}$ \\
\hline
\end{tabular}

Table 7 shows that the proposed model provides better results compared to Zhang et al. [50] and Dye et al. [10] either when trade-credit is applied or not applied. The table also noticed that the trade-credit proposed model's implementations give better results in both cases.

\section{Sensitivity AnALYSiS}

In the above-depicted numerical examples, the affectability investigation performed distinctly for Case 3 as it gives the ideal outcome for the given arrangement of information. The consequence of below or above assessment of the inventory features is studied of the chain. By changing the critical factors from $-20 \%$ to $+20 \%$, the process of sensitivity is considered. The following table shows the data during the analyses of sensitivity one gets.

One can conclude from the above Table 8. As:

\section{Observation 1}

$\pi^{*}$ increases with the decrease in the parameters $b, c_{p}, c_{1}, K, c_{3}, \delta, M$. When $a_{1}$ increases or decreases, moreover, there is no effect on $\pi^{*}$. It is observed that the increase or decrease in the total profit mostly depends on the decision variables of selling price and PTI of the item, except in trade-credit. The total profit is exceedingly sensitive concerning $b, a$ whereas with respect to $a_{1}, \delta, \gamma$ it is less sensitive.

\section{Observation 2}

With the decreases in the value of $b, t_{1}, c_{p}$, the value of $S^{*}$ increases. Furthermore, $S^{*}$ has no impact after the value of $K, a_{1}$ increases or decreases. Once the expense of buying the item is accessible at a lower value, the retailer wants to stock more goods. Therefore, when the manufacturer extends the trade-credit period to the retailer, he always wants to add more goods to get customers' attention to sell more products and increase profit.

\section{Observation 3}

With the decreases in the values of $I_{e}, c_{p}, c_{3}$ the optimal shortages $R^{*}$ rise. Furthermore, with the increase or decreases of the parameters $K, a_{1}$ there is no effect on $R^{*}$. Also, it is detected that with the growth of $\delta$, the volume of shortages declines, and if it is appropriate to limitlessness, then shortages become zero, meaning $R^{*}$ drops to zero.

\section{Observation 4}

$p^{*}$ increases at the point as soon as the estimation of the parameters $b, t_{1}, I_{e}$, declines. Besides, there is no influence on $p^{*}$ at the point when the estimation of the parameters $A, K, \gamma, a_{1}$ increases or decreases. Nevertheless, with the increase in the selling price, the retailer wants to vend different products to extend the total cycle time and condense the shortage to maximize profits. 
TABLE 8. The analysis of sensitivity for different parameters.

\begin{tabular}{|c|c|c|c|c|c|c|c|}
\hline \multirow[t]{2}{*}{ Constraint } & \multirow{2}{*}{$\begin{array}{l}\% \text { Variation } \\
\text { in Constraint }\end{array}$} & \multirow{2}{*}{$\begin{array}{l}\% \text { Variation } \\
\text { in } \\
\pi^{*}\end{array}$} & \multicolumn{5}{|c|}{$\%$ Variation in } \\
\hline & & & $S^{*}$ & $R^{*}$ & $p^{*}$ & $\xi^{*}$ & $T^{*}$ \\
\hline \multirow[t]{4}{*}{$b$} & -20 & 81.03 & 15.61 & -1.84 & 18.62 & 2.1 & 0 \\
\hline & -10 & 35.38 & 7.59 & -0.27 & 8.28 & 1.01 & 0 \\
\hline & 10 & -27.96 & -7.22 & -0.84 & -6.77 & -0.93 & 0 \\
\hline & 20 & -50.38 & -14.1 & -2.65 & -12.42 & -1.8 & 0 \\
\hline \multirow[t]{4}{*}{$a$} & -20 & -77.03 & -33.95 & -23.08 & -14.9 & -2.21 & 0 \\
\hline & -10 & -42.17 & -17.2 & -10.89 & -7.45 & -1.03 & 0 \\
\hline & 10 & 49.51 & 17.58 & 9.78 & 7.45 & 0.92 & 0 \\
\hline & 20 & - & - & - & - & - & - \\
\hline \multirow[t]{4}{*}{$C_{p}$} & -20 & 9.16 & 4.6 & 4.19 & -1.47 & -15.97 & 0 \\
\hline & -10 & 4.44 & 2.18 & 2.09 & -0.72 & -7.6 & 0 \\
\hline & 10 & -4.21 & -1.99 & -2.09 & 0.69 & 6.96 & 0 \\
\hline & 20 & -8.21 & -3.82 & -4.17 & 1.36 & 13.39 & 0 \\
\hline \multirow[t]{4}{*}{$c_{1}$} & -20 & 25.37 & 13.39 & -15.53 & -3.4 & 19.62 & 0 \\
\hline & -10 & - & - & - & - & - & - \\
\hline & 10 & -10.94 & -6.29 & 6.51 & 1.52 & -8.79 & 0 \\
\hline & 20 & -20.88 & -12.28 & 12.28 & 2.94 & -17.08 & 0 \\
\hline \multirow[t]{4}{*}{$c_{2}$} & -20 & 0.215 & -0.25 & 1.14 & -0.06 & -9.26 & 0 \\
\hline & -10 & - & - & - & - & - & - \\
\hline & 10 & - & - & - & - & - & - \\
\hline & 20 & - & - & - & 0 & - & - \\
\hline \multirow[t]{4}{*}{$c_{3}$} & -20 & 1.878 & -2.21 & 10.07 & -0.53 & -10.62 & 0 \\
\hline & -10 & - & - & - & - & - & - \\
\hline & 10 & -0.808 & 0.94 & -4.37 & 0.22 & -8.42 & 0 \\
\hline & 20 & -1.55 & 1.8 & -8.36 & 0.42 & -7.83 & 0 \\
\hline \multirow[t]{4}{*}{$a_{1}$} & -20 & 0 & 0 & 0 & 0 & +24.97 & 0 \\
\hline & -10 & 0 & 0 & 0 & 0 & +11.1 & 0 \\
\hline & 10 & 0 & 0 & 0 & 0 & -9.08 & 0 \\
\hline & 20 & 0 & 0 & 0 & 0 & -16.65 & 0 \\
\hline \multirow[t]{4}{*}{$\theta$} & -20 & - & - & - & - & - & - \\
\hline & -10 & - & - & - & - & - & - \\
\hline & 10 & 5.16 & 4.1 & -0.82 & -0.76 & 13.27 & 0 \\
\hline & 20 & 9.63 & 7.82 & -1.49 & -1.41 & 25.65 & 0 \\
\hline \multirow[t]{4}{*}{$\delta$} & -20 & - & - & - & - & - & - \\
\hline & -10 & - & - & - & - & - & - \\
\hline & 10 & - & - & - & - & - & - \\
\hline & 20 & -2.45 & 2.48 & -14.29 & 0.5 & -7.43 & 0 \\
\hline \multirow[t]{4}{*}{$K$} & -20 & +9.06 & 0 & 0 & 0 & -9.08 & 0 \\
\hline & -10 & +4.53 & 0 & 0 & 0 & -9.08 & 0 \\
\hline & 10 & -4.53 & 0 & 0 & 0 & -9.08 & 0 \\
\hline & 20 & -9.05 & 0 & 0 & 0 & -9.08 & 0 \\
\hline \multirow[t]{4}{*}{$t_{1}$} & -20 & -2.62 & +0.75 & -0.61 & +0.41 & -8.1 & 0 \\
\hline & -10 & -1.31 & +0.37 & -0.3 & +0.21 & -8.58 & 0 \\
\hline & 10 & 1.33 & -0.36 & 0.29 & -0.21 & -9.59 & 0 \\
\hline & 20 & 2.66 & -0.7 & 0.57 & -0.41 & -10.11 & 0 \\
\hline
\end{tabular}

Notes. N.B. the sign (-) use in Table 8, for non-optimal solution. 
TABLE 8. continued.

\begin{tabular}{|c|c|c|c|c|c|c|c|}
\hline \multirow[t]{2}{*}{ Constraint } & \multirow{2}{*}{$\begin{array}{l}\% \text { Variation } \\
\text { in Constraint }\end{array}$} & \multirow[t]{2}{*}{ Variation } & \multicolumn{5}{|c|}{$\%$ Variation in } \\
\hline & & & $S^{*}$ & $R^{*}$ & $p^{*}$ & $\xi^{*}$ & $T^{*}$ \\
\hline \multirow[t]{4}{*}{$\gamma$} & -20 & -1.05 & -0.73 & -0.73 & 0 & -9.08 & 0 \\
\hline & -10 & -0.53 & -0.36 & -0.37 & 0 & -9.08 & 0 \\
\hline & 10 & 0.53 & 0.36 & 0.36 & 0 & -9.08 & 0 \\
\hline & 20 & 1.07 & 0.73 & 0.73 & 0 & -9.08 & 0 \\
\hline \multirow[t]{4}{*}{$A$} & -20 & -6.34 & -4.37 & -4.36 & 0 & -9.08 & 0 \\
\hline & -10 & -3.03 & -2.09 & -2.09 & 0 & -9.08 & 0 \\
\hline & 10 & 2.8 & 1.92 & 20.96 & 0 & -9.08 & 0 \\
\hline & 20 & 5.4 & 3.71 & 3.71 & 0 & -9.08 & 0 \\
\hline \multirow[t]{4}{*}{$M$} & -20 & 2.67 & -21.26 & -12.52 & -2.33 & -21.18 & -20 \\
\hline & -10 & 1.8 & -10.56 & -6.23 & -1.14 & -15.08 & -10 \\
\hline & 10 & -2.46 & 10.35 & 6.13 & 1.11 & -3.19 & 10 \\
\hline & 20 & -5.39 & 20.41 & 12.12 & 2.2 & 2.59 & 20 \\
\hline \multirow[t]{4}{*}{$I_{e}$} & -20 & -4.1 & -1.36 & 1.2 & 0.31 & -0.35 & 0 \\
\hline & -10 & -2.05 & -0.67 & 0.6 & 0.15 & -0.18 & 0 \\
\hline & 10 & 2.06 & 0.67 & -0.59 & -0.15 & 0.17 & 0 \\
\hline & 20 & 4.13 & 1.33 & -1.18 & -0.3 & 0.34 & 0 \\
\hline
\end{tabular}

\section{Observation 5}

$\xi^{*}$ increases at the time when the assessment of the factors $b, a_{1}, c_{1}$, increases. Moreover, the preservation technology investment $\xi^{*}$ is compassionate relating to $a_{1}$. There is a parallel correlation between $p^{*}$ and the value of the factor $I_{e}, M$. By the intensification of the value of the simulation coefficient $a_{1}$, the value of preservation investment decreases.

\section{Observation 6}

The changes in $T^{*}$ are dependent on the trade-credit policy $M$. Moreover, there is no effect on $R$ concerning other factors under trade-credit period conditions. There is a close connection concerning total cycle length and trade-credit period; once retailers obtain a more significant trade-credit period, they want to increase the cycle length.

\section{Performance COMParison}

It is the fundamental question of why trade-credit and PT investment are used in this projected model. To validate that here the plot is done by taking into account the fact that (i) with the preservation and without preservation technology investment (PTI) (ii) with trade-credit and trade-credit policy and (iii) if both tradecredit and PTI both are absent. The look of a two-dimensional graph concerning selling price and total profit is presented below.

\section{Observations}

- It is clear from the above figures (Figs. 6-8) that the profit is low compared to both without trade-credit and PTI.

- The situation is also noted that when selling products is very high, the demand becomes low. Accordingly, the retailer wishes to hold products further. He needs to invest extra amounts in PT, so the profit has become intense.

- As the retailer needs to hold products more when the selling price is high, he needs to allocate more money to hold products, which will affect total profit. 


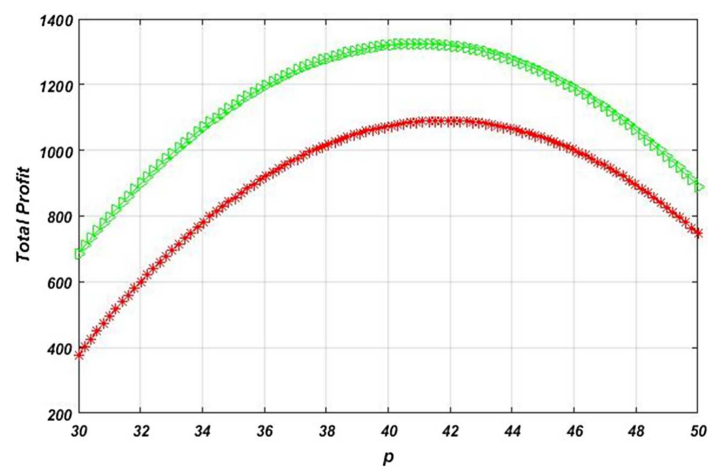

FIGURE 6. Redline for without preservation technology and green line for preservation technology investment.

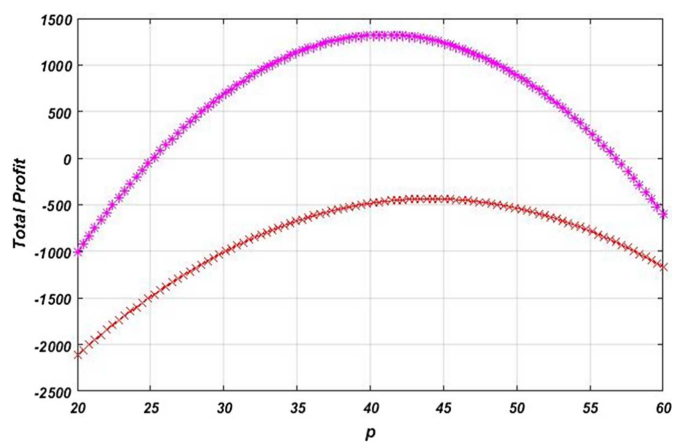

FiguRE 7. Redline for without trade-credit and pink line with trade-credit policy.

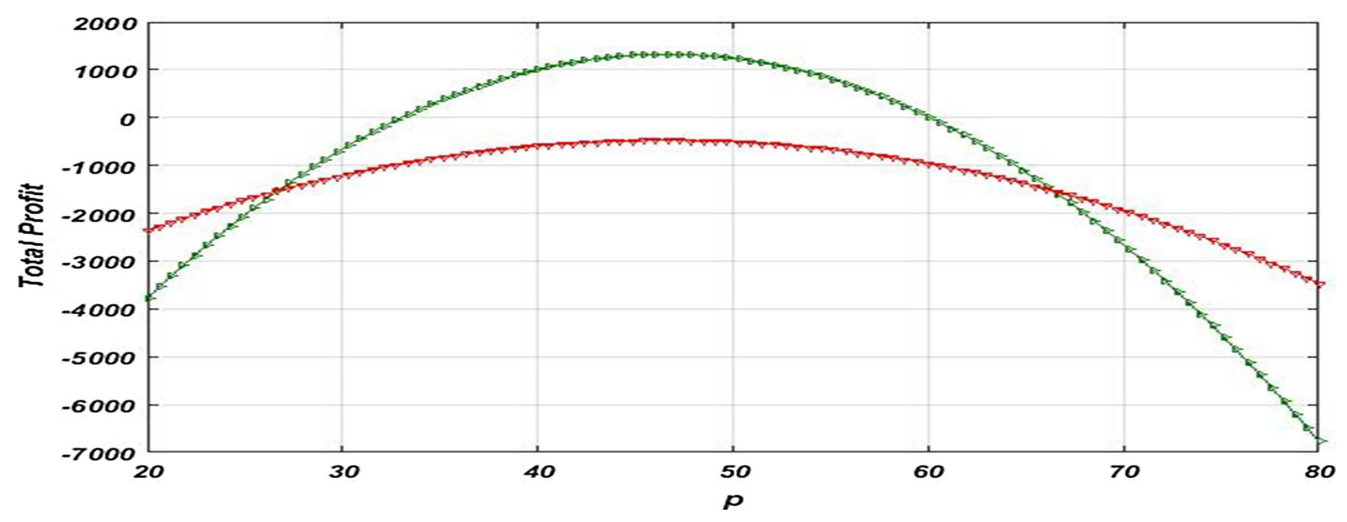

FIGURE 8. Redline for without trade-credit, preservation technology investment (PTI), and green line for both. 
- When the selling price is large enough compared to other values of the proposed model's parameter, the retailer can get more profit than the technology in some cases. To get maximum profit, he must need to avail trade-credit policy investment in PT.

\section{MANAGERIAL INSIGHTS}

Marketing strategies and preserving facilities are acting an imperative role in the retailing business. This proposed study simultaneously explores some significant results for the industry managers about using tradecredit and preservation technology in the retailing business appropriately.

- This proposed study provides how long a manager requisite to invest in preservation technology besides indicates how much one should invest in diminishing deterioration to secure profit that is more significant in business.

- From this study, a manager gets the opportunity to acquaint with the proper use of trade credit policy. The manager can quickly know how long trade-credit he can offer to his customer in beneficiary mode.

- It has been clear that when the selling price is low, then stock finished quickly, and the manger avails more profit. However, the increase in selling price reduced the products' sales; thus, the retailer needs to hold that product for a long time, which causes some expenses. Therefore, a manager can learn some pricing strategies from the prior study.

- This model will provide information about how simultaneously one can fine-tune trade-credit and preservation technology for a more significant profit.

\section{Conclusions}

The proposed model is known as a general structure, which included the prior models (as mentioned before) regarding advertisement frequency with price-dependent demand. In this paper, preservation technology has been introduced where the decay rate of exceedingly deteriorated items is regulated through investment. As a result, it shows that investing in PT minimizes the deterioration rate and thus prolongs the new deteriorating items. In this proposed model, the trade-credit policy is applied in retailers' perceptions to make business more flexible and profitable. Moreover, both strategies simultaneously successfully implement the model, and more importantly, it provides a better profit for the retailer. However, plugging trade-credit in this model also extends Zhang et al.'s [50] idea where they did not use any credit policy. The implementation of trade-credit to the model of Zhang et al. [50] provides better profit for the retailer. Some theoretical results provided an effective solution mechanism for achieving the optimal time cycle, optimal selling price, and PT investment strategies while increasing the total profit over a period. Several examples are carried out to show the significance of investment in PT and trade-credit strategy. The concavity of the profit function is shown graphically through the MATLAB software. The sensitivity of altered parameters is analyzed by making variations in one parameter, while the remaining parameters are the same, which plays a vital role in making better management decisions for business firms.

One of this study's significant limitations is constant deterioration (although an example is provided), while variable deterioration is more suitable in preservation technology. One can further extend this proposed model by taking factors such as probabilistic demand rate, ramp-type demand, variable holding cost, quantity discounts, and inflation effects. In the context of trade-credit policy, this model can be extended by using two trade-credit policy levels. The model can also be computed under the fuzzy environment.

Acknowledgements. The work is supported by the National Research Foundation of Korea (NRF) grant, funded by the Korea Government (MSIT) (NRF-2020R1F1A1064460). 


\section{REFERENCES}

[1] S.P. Aggarwal and C.K. Jaggi, Ordering policies of deteriorating items under permissible delay in payments. J. Oper. Res. Soc. 46 (1995) 658-662.

[2] A.N.M. Agi and H.N. Soni, Joint pricing and inventory decisions for perishable products with age-, stock-, and price-dependent demand rate. J. Oper. Res. Soc. 71 (2020) 85-99.

[3] R. Begum, R.R. Sahoo and S.K. Sahu, A replenishment policy for items with price-dependent demand, time-proportional deterioration and no shortages. Int. J. Syst. Sci. 43 (2012) 903-910.

[4] A. Cambini and L. Martein, Generalized Convexity and Optimization: Theory and Application. Springer-Verlag Berlin Heidelberg, USA (2009).

[5] L.E. Cárdenas-Barrón and S.S. Sana, A production-inventory model for a two-echelon supply chain when demand is dependent on sales teams' initiatives. Int. J. Prod. Econ. 155 (2014) 249-258.

[6] L.E. Cárdenas-Barrón, J.L.G. Velarde, G. Trevino-Garza and D. Garza-Nunez, Heuristic algorithm based on reduce and optimize approach for a selective and periodic inventory routing problem in a waste vegetable oil collection environment. Int. J. Prod. Econ. 211 (2019) 44-59.

[7] S.C. Das, A.M. Zidan, A.K. Manna, A.A. Shaikh and A.K. Bhunia, An application of preservation technology in inventory control system with price dependent demand and partial backlogging. Alexandria Eng. J. 59 (2020) 1359-1369.

[8] B.K. Dey, B. Sarkar, M. Sarkar and S. Pareek, An integrated inventory model involving discrete setup cost reduction, variable safety factor, selling price dependent demand, and investment. RAIRO:OR $\mathbf{5 3}$ (2019) 39-57.

[9] C.Y. Dye, The effect of preservation technology investment on a non-instantaneous deteriorating inventory model. Omega 41 (2013) 872-880.

[10] C.Y. Dye and T.P. Hsieh, An optimal replenishment policy for deteriorating items with effective investment in preservation technology. Eur. J. Oper. Res. 218 (2012) 106-112.

[11] P. Gautam, A. Kishore, A. Khanna and C.K. Jaggi, Strategic defect management for sustainable green supply chain. J. Cleaner Prod. 233 (2019) 226-241.

[12] S.K. Goyal, Economic order quantity under conditions of permissible delay in payments. J. Oper. Res. Soc. 36 (1985) $335-338$.

[13] Y. He and H. Huang, Optimizing inventory and pricing policy for seasonal deteriorating products with preservation technology investment. J. Ind. Eng. 2013 (2013) 793568.

[14] M.R. Hasan and A. Md Mashud, An economic order quantity model for decaying products with the frequency of advertisement, selling price and continuous time dependent demand under partially backlogged shortage. Int. J. Suppl. Oper. Manage.6 (2019) $296-314$.

[15] M.W. Iqbal and B. Sarkar, Application of preservation technology for lifetime dependent products in an integrated production system. J. Ind. Manage. Optim. 16 (2020) 141-167.

[16] C.K. Jaggi, S. Goel and M. Mittal, Credit financing in economic ordering policies for imperfect quality items with allowable shortages. Appl. Math. Comput. 219 (2013) 5268-5282.

[17] C.K. Jaggi, S. Tiwari and S.K. Goel, Credit financing in economic ordering policies for non-instantaneous deteriorating items with price dependent demand and two storage facilities. Ann. Oper. Res. 248 (2017) 253-280.

[18] C.K. Jaggi, S. Tiwari, M. Gupta and H.M. Wee, Impact of credit financing, storage system and changing demand on investment for deteriorating items. Int. J. Syst. Sci.: Oper. Logistics 6 (2019) 142-161.

[19] C.K. Jaggi, M. Gupta, A. Kausar and S. Tiwari, Inventory and credit decisions for deteriorating items with displayed stock dependent demand in two-echelon supply chain using Stackelberg and Nash equilibrium solution. Ann. Oper. Res. 274 (2019) 309-329.

[20] A. Khanna, A. Kishore, B. Sarkar and C.K. Jaggi, Supply chain with customer-based two-level credit policies under an imperfect quality environment. Mathematics 6 (2018) 299.

[21] G. Li, X. He, J. Zhou and H. Wu, Pricing, replenishment and preservation technology investment decisions for non-instantaneous deteriorating items. Omega 84 (2019) 114-126.

[22] G. Liu, J. Zhang and W. Tang, Joint dynamic pricing and investment strategy for perishable foods with price-quality dependent demand. Ann. Oper. Res. 226 (2015) 397-416.

[23] L. Lu, J. Zhang and W. Tang, Optimal dynamic pricing and replenishment policy for perishable items with inventory-leveldependent demand. Int. J. Syst. Sci. 47 (2016) 1480-1494.

[24] W. Luo, An integrated inventory system for perishable goods with backordering. Comput. Ind. Eng. 34 (1998) 685-693.

[25] A.H.M. Mashud, M.A. Khan, M.S. Uddin and M.N. Islam, A non-instantaneous inventory model having different deterioration rates with stock and price dependent demand under partially backlogged shortages. Uncertain Supply Chain Manage. 6 (2018) 49-64.

[26] A.H.M. Mashud, M.R. Hasan, H.M. Wee and Y. Daryanto, Non-instantaneous deteriorating inventory model under the joined effect of trade-credit, preservation technology and advertisement policy. Kybernetes 49 (2019) 1645-1674.

[27] A.H.M. Mashud, H.M. Wee and C.V. Huang, Preservation technology investment, trade credit and partial backordering model for a non-instantaneous deteriorating inventory. RAIRO:OR 55 (2021) S51-S77.

[28] A.H.M. Mashud, H.M. Wee, B. Sarkar and Y.H. Chiang Li, A sustainable inventory system with the advanced payment policy and trade-credit strategy for a two- warehouse inventory system. Kybernetes 50 (2021) 1321-1348.

[29] U. Mishra, J.T. Aguilera, S. Tiwari and L.E. Cárdenas-Barrón, Retailer's joint ordering, pricing, and preservation technology investment policies for a deteriorating item under permissible delay in payments. Math. Prob. Eng. 5 (2018) 1-14. 
[30] M. Mittal, A. Khanna and C.K. Jaggi, Retailer's ordering policy for deteriorating imperfect quality items when demand and price are time-dependent under inflationary conditions and permissible delay in payments. Int. J. Procurement Manage. 10 (2017) 461-494.

[31] M. Mittal, B. Sarkar and D. Shin, Effects of human errors and trade-credit financing in a two-echelon supply chain model. Eur. J. Ind. Eng. 12 (2018) 465-503.

[32] L.Y. Ouyang, K.S. Wu and C.T. Yang, A study on an inventory model for non-instantaneous deteriorating items with permissible delay in payments. Comput. Ind. Eng. 51 (2006) 637-651.

[33] M. Palanivel and R. Uthayakumar, Finite horizon EOQ model for non-instantaneous deteriorating items with price and advertisement dependent demand and partial backlogging under inflation. Int. J. Syst. Sci. 46 (2013) 1-12.

[34] M. Palanivel and R. Uthayakumar, An inventory model with imperfect items, stock dependent demand and permissible delay in payments under inflation. RAIRO:OR 50 (2016) 473-489.

[35] S. Panda, N.M. Modak and L.E. Cárdenas-Barrón, Coordination and benefit sharing in a three-echelon distribution channel with deteriorating product. Comput. Ind. Eng. 113 (2017) 630-645.

[36] S. Schaible, Fractional programming. Math. Methods Oper. Res. 27 (1983) 39-54.

[37] N.H. Shah, H.N. Soni and K.A. Patel, Optimizing inventory, marketing policy for non-instantaneous deteriorating items with generalized type deterioration, and holding cost rates. Omega 41 (2013) 421-430.

[38] B. Sarkar, An inventory model with reliability in an imperfect production process. Appl. Math. Comput. 28 (2012) $4881-4891$.

[39] B. Sarkar, A Production inventory model with probabilistic deterioration in two echelon supply chain management. Appl. Math. Model. 37 (2013) 3138-3151.

[40] A.A. Shaikh, A.H. Md Mashud, M.S. Uddin and A.A. Khan, Non-instantaneous deterioration inventory model with price and stock dependent demand for fully backlogged shortages under inflation. Int. J. Bus. Forecast. Market. Intell. 3 (2017) 152-164.

[41] H.N. Soni and D.N. Suthar, Pricing and inventory decisions for non-instantaneous deteriorating items with price and promotional effort stochastic demand. J. Control Decis. 6 (2018) 191-215.

[42] A.A. Taleizadeh, S. Rezvan-Beydokhti and L.E. Cárdenas-Barrón, Joint determination of the optimal selling price, refund policy and quality level for ccomplementary products in online purchasing. Eur. J. Ind. Eng. 12 (2018) 332-363.

[43] J.T. Teng, J. Min and Q. Pan, Economic order quantity model with trade-credit financing for non-decreasing demand. Omega 40 (2012) 328-335.

[44] J.T. Teng, H.L. Yang and M.S. Chern, An inventory model for increasing demand under two levels of trade-credit linked to order quantity. Appl. Math. Model. 37 (2013) 7624-7632.

[45] S. Tiwari, H.M. Wee and S. Sarkar, Lot-sizing policies for defective and deteriorating items with time-dependent demand and trade credit. Eur. J. Ind. Eng. 11 (2017) 683-703.

[46] Y.C. Tsao and G.J. Sheen, Dynamic pricing, promotion and replenishment policies for a deteriorating item under permissible delay in payments. Comput. Oper. Res. 35 (2008) 3562-3580.

[47] M. Ullah, B. Sarkar and I. Asghar, Effects of preservation technology investment on waste generation in a two-Echelon supply chain model. Mathematics 7 (2019) 189.

[48] R. Yadav, S. Pareek and M. Mittal, Supply chain models with imperfect quality items when end demand is sensitive to price and marketing expenditure. RAIRO:OR $\mathbf{5 2}$ (2018) 725-742.

[49] C.T. Yang, C.Y. Dye and J.F. Ding, Optimal dynamic trade-credit and preservation technology allocation for a deteriorating inventory model. Comput. Ind. Eng. 87 (2015) 356-369.

[50] J. Zhang, Z. Bai and W. Tang, Optimal pricing policy for deteriorating items with preservation technology investment. J. Ind. Manage. Optim. 10 (2014) 1261-1277. 